Check for updates

Cite this: Analyst, 2021, 146, 770

Received 27th July 2020,

Accepted 18th November 2020

DOI: $10.1039 / \mathrm{d} 0 \mathrm{an} 01482 \mathrm{f}$

rsc.li/analyst

\section{Discrimination of bacteria using whole organism fingerprinting: the utility of modern physicochemical techniques for bacterial typing}

\author{
Najla AlMasoud, ${ }^{a}$ Howbeer Muhamadali, ${ }^{b}$ Malama Chisanga, $\dagger^{\mathrm{c}}$ Haitham AlRabiah, ${ }^{\mathrm{d}}$ \\ Cassio A. Limab and Royston Goodacre (iD *b
}

\section{Introduction}

Unequivocal identification of bacteria is essential for several clinical and biological applications, such as the treatment of disease in animals and plants, where accurate diagnosis is required for an efficient and effective strategy to eradicate infectious microorganisms. ${ }^{1}$ Accurate diagnosis is also important in limiting the possibility of toxicity to host cells as well as reducing the risk of developing antimicrobial resistance

\footnotetext{
${ }^{a}$ Department of Chemistry, College of Science, Princess Nourah bint Abdulrahman University, Riyadh 11671, Saudi Arabia

${ }^{b}$ Department of Biochemistry and Systems Biology, Institute of Systems, Molecular and Integrative Biology, University of Liverpool, Biosciences Building, Crown Street, Liverpool L69 7ZB, UK. E-mail: roy.goodacre@liverpool.ac.uk

${ }^{c}$ School of Chemistry and Manchester Institute of Biotechnology,

University of Manchester, Manchester, UK

${ }^{d}$ Department of Pharmaceutical Chemistry, College of Pharmacy,

King Saud University, P.O. Box 2457, Riyadh, 11451, Saudi Arabia

$\dagger$ Present address: School of Mathematics and Natural Sciences, Department of Chemistry, Copperbelt University, Kitwe, Zambia.
}

(AMR). In addition, detection and identification of bacteria play a key role in quality control in the food industry, ${ }^{2}$ while adequate control of bacteria and fungi is important with food biotechnology, for example for the fermentation of foodstuffs and production of microbial metabolites used as food ingredients such as acetic acid and citric acid. ${ }^{3}$

A desirable technique for bacterial characterisation and identification should fulfil the following criteria: provision and identification within universal bacterial detection, the ability to detect and identify emerging and uncharacterised bacteria unequivocally, high throughput analysis, low operation cost and minimal sample preparation time. ${ }^{4}$

\section{Traditional bacterial typing}

The first step for bacterial identification is the isolation of the bacteria from the complex sample that they reside in. For human samples this may be something relatively non-complex like urine or blood, to faeces where many commensal bacteria reside as part of the natural microflora; for environmental samples this could be for example a soil specimen. In order to 
Table 1 Advantages and disadvantages of traditional methods used to characterise bacteria

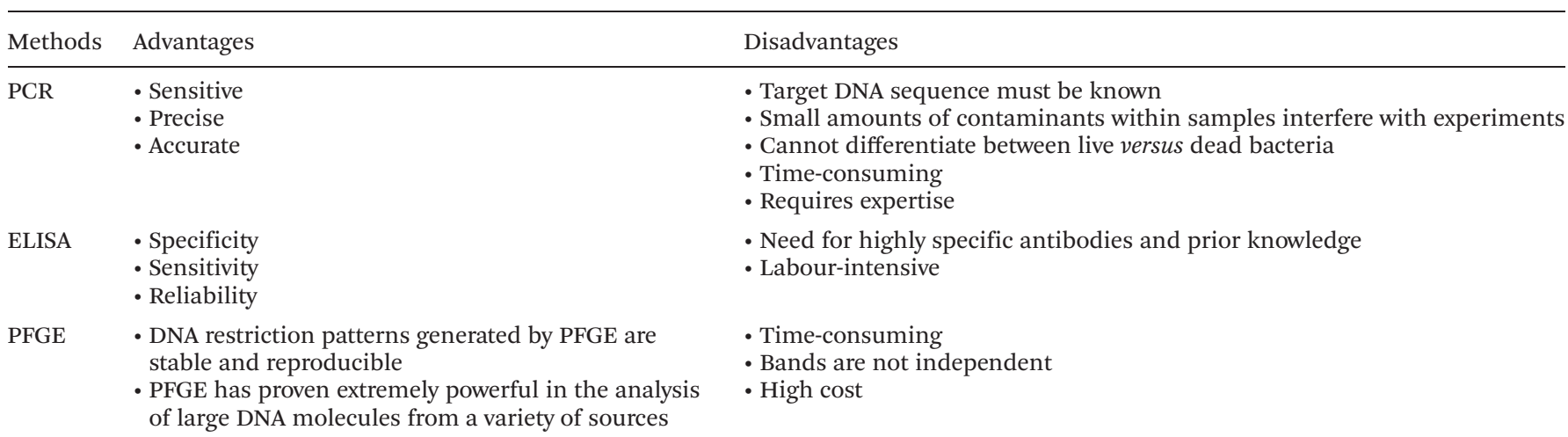

achieve isolation of bacteria, microbiologists use selective and/ or differential media. As the names suggested these media first enrich for a particular bacterial species. This requires the clinician/microbiologist to have prior information as to what the infective organism may be. In addition, some media are also differential in nature so that the microorganism that a microbiologist is looking for becomes coloured in some particular way. This is usually due to a specific enzyme reaction turning a substrate into a chromogenic product that can be easily seen by eye. ${ }^{5}$ Following isolation of the bacteria a range of tests are used for identification purposes. It should be stressed that isolation of bacteria is a relatively slow process which is dependent on the growth rate of the microbes: taking days for fast-growing bacteria like Escherichia coli, to several weeks for slow growing bacteria like Mycobacterium tuberculosis.

A great deal of research has demonstrated the application of a wide range of laboratory techniques to classify and identify bacteria; ${ }^{6}$ these include physiological and biochemical tests, such as cell morphology assessment and analytical profile index (API) ${ }^{7}$ immuno-assays such as the enzyme-linked immunosorbent assay (ELISA), ${ }^{8}$ as well as genetic analysis (DNA sequencing) using polymerase chain reaction (PCR) ${ }^{4}$ and pulsed-field gel electrophoresis (PFGE). ${ }^{9}$ However, the majority of these standard microbiological approaches tend to be timeconsuming, cannot differentiate between dead and live cells and are labour and cost-intensive (Table 1). Therefore, this highlights the need for new alternative and/or complementary approaches that offer lower turnaround time, high reliability and cost-effective bacterial analyses. ${ }^{10}$

\section{Physicochemical methods for bacterial typing}

Modern analytical techniques, including mass spectrometry ${ }^{11}$ and spectroscopic techniques, ${ }^{12}$ have demonstrated great potential in classification, identification and characterisation of bacteria. Analytical techniques such as matrix-assisted laser desorption/ionisation mass spectrometry (MALDI-MS), ${ }^{13}$ electrospray ionisation mass spectrometry (ESI-MS), ${ }^{14}$ Raman spectroscopy ${ }^{15}$ and Fourier-transform infrared (FT-IR) spectroscopy ${ }^{16}$

Najla AlMasoud obtained her BSc in Chemistry from Princess Nourah bint Abdulrahman University (PNU), Saudi Arabia. Najla was also awarded her Masters and PhD degrees from the University of Manchester, $U K$ and is currently an Assistant Professor in Chemistry and a member of the IRB community at $P N U$. Prior to this, she managed the community services at the college of science at PNU from 2016 to 2019. Najla published a number of scientific papers in international journals with regard to modern analytical techniques for bacterial characterization including discrimination, rapid detection of foodborne bacteria, environmental metabolomics, and analysis of pharmaceutical compounds using enhanced Raman scattering. Najla is interested in nanotechnology, in line with analytical techniques.

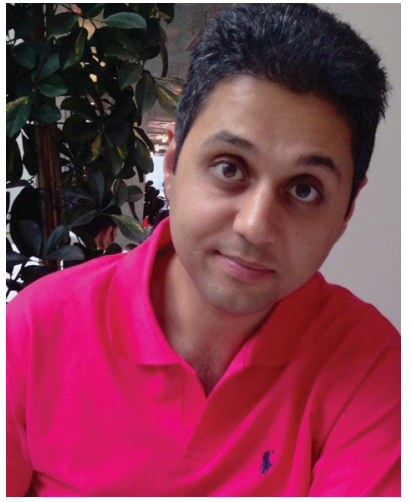

Howbeer Muhamadali
Howbeer Muhamadali received first class honours in Microbiology at the Manchester Metropolitan University in 2010. In 2011, he successfully completed an MPhil in geomicrobiology at the University of Manchester and continued with a PhD program (Biotechnology/Metabolomics) working on metabolomics investigations of different microbial bioprocesses using various analytical techniques and multivariate statistical analysis approaches. In Dec 2019, he started his own group at the University of Liverpool as a tenure track fellow, working on the applications of molecular imaging and metabolomics techniques for better understanding of antimicrobial resistance at single cell and community (biofilm) levels. 


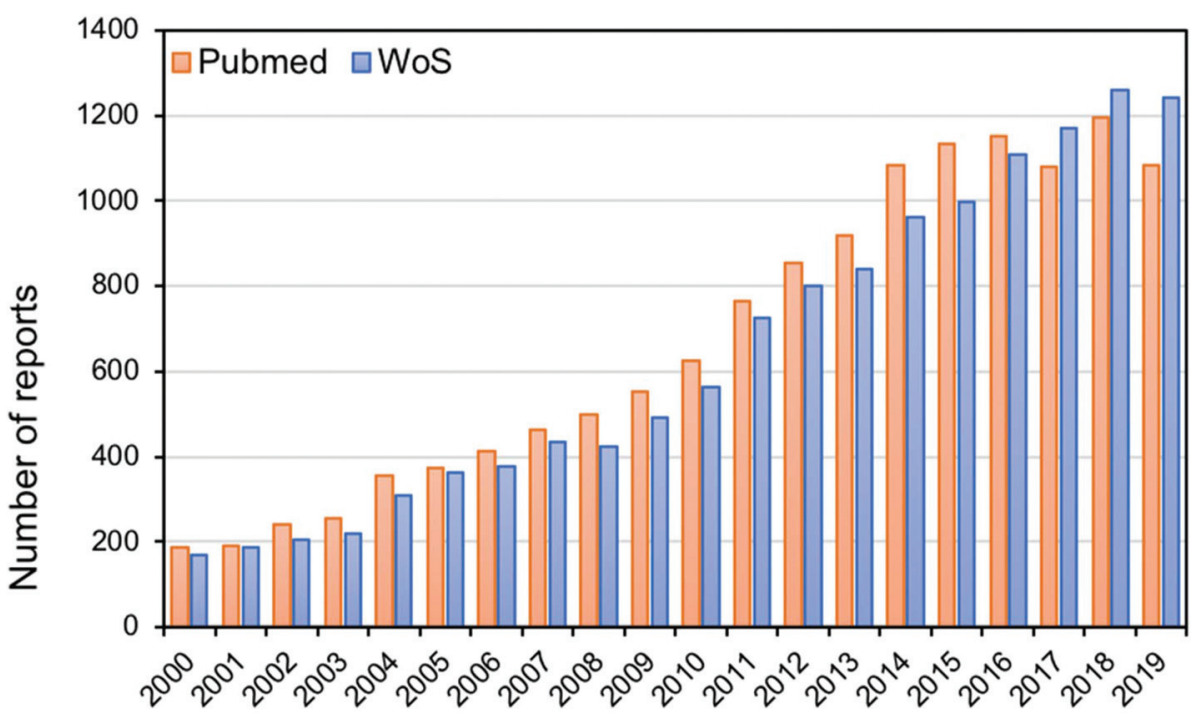

Fig. 1 Bar chart showing the number of publications from 2000 to 2019 in PubMed and Web of Science (WoS) bibliometric repositories using the search terms ["bacterial typing" AND ("mass spectrometry" OR "vibrational spectroscopy")] for modern analytical techniques used in bacterial typing, classification or identification.

have undoubtedly gained increasing importance in many microbiology and clinical laboratories due to their efficiency in laboratory diagnosis of microbial infections. A simple literature search covering the last 18 years using suitable keywords (e.g. ['bacterial typing' AND \{'mass spectrometry' OR 'vibrational spectroscopy'\}]) in different bibliometric repositories shows the rapid and steady increase in the number of publications in bacterial typing, as shown in Fig. 1. A Web of Science search showed a six-fold increase in publications in this period, suggesting that more biological and clinical laboratories are opting for the use of these analytical methods in bacterial classification and

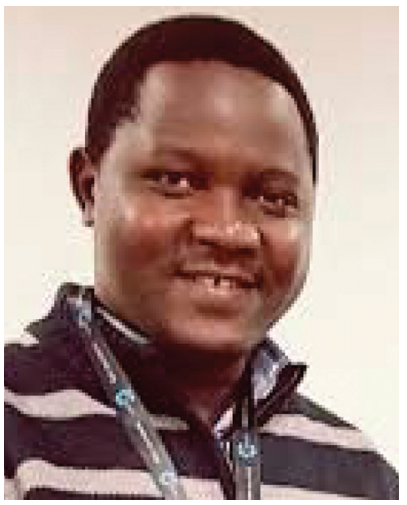

Malama Chisanga
Malama Chisanga graduated with top class distinction in Chemistry from Copperbelt University, Zambia in 2012, before completing an MSc at the University of Manchester in 2014. In 2020, he successfully completed his PhD in Analytical Chemistry under the mentorship of Professor Roy Goodacre and Professor Nick Lockyer at the University of Manchester. Malama's project involved the development of SERS, Raman spectroscopy and FT-IR spectroscopy combined with multivariate statistical techniques to probe metabolic functions and phenotypic characteristics of clinically and industrially relevant bacteria within complex microbial communities. He re-joined Roy Goodacre's research laboratories at the University of Liverpool in 2020 where he worked as an honorary research associate. Malama's current research involves the investigation of kinetics of substrate uptake and cross-feeding experiments of metabolites among microbes residing in mixed microbial consortia using several analytical approaches including SERS, Raman spectroscopy, and GC-MS platforms.

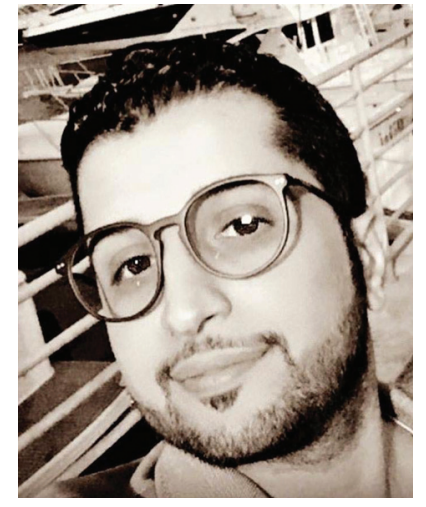

Haitham AlRabiah
Haitham AlRabiah is an Associate Professor in the Department of Pharmaceutical Chemistry at King Saud University, where he has been a faculty member since 2006. Haitham completed his PhD at the University of Manchester in metabolomics under the supervision of Professor Roy Goodacre, his MSc in Pharmaceutical Analysis at the University of Strathclyde and his undergraduate studies at the College of Pharmacy at KSU. His research interests lie in the area of pharmaceutical analysis, drug metabolism, biomarker diagnostics and metabolomics. He has co-authored more than 60 original research articles in his field of interest, and supervised several PhD students. 


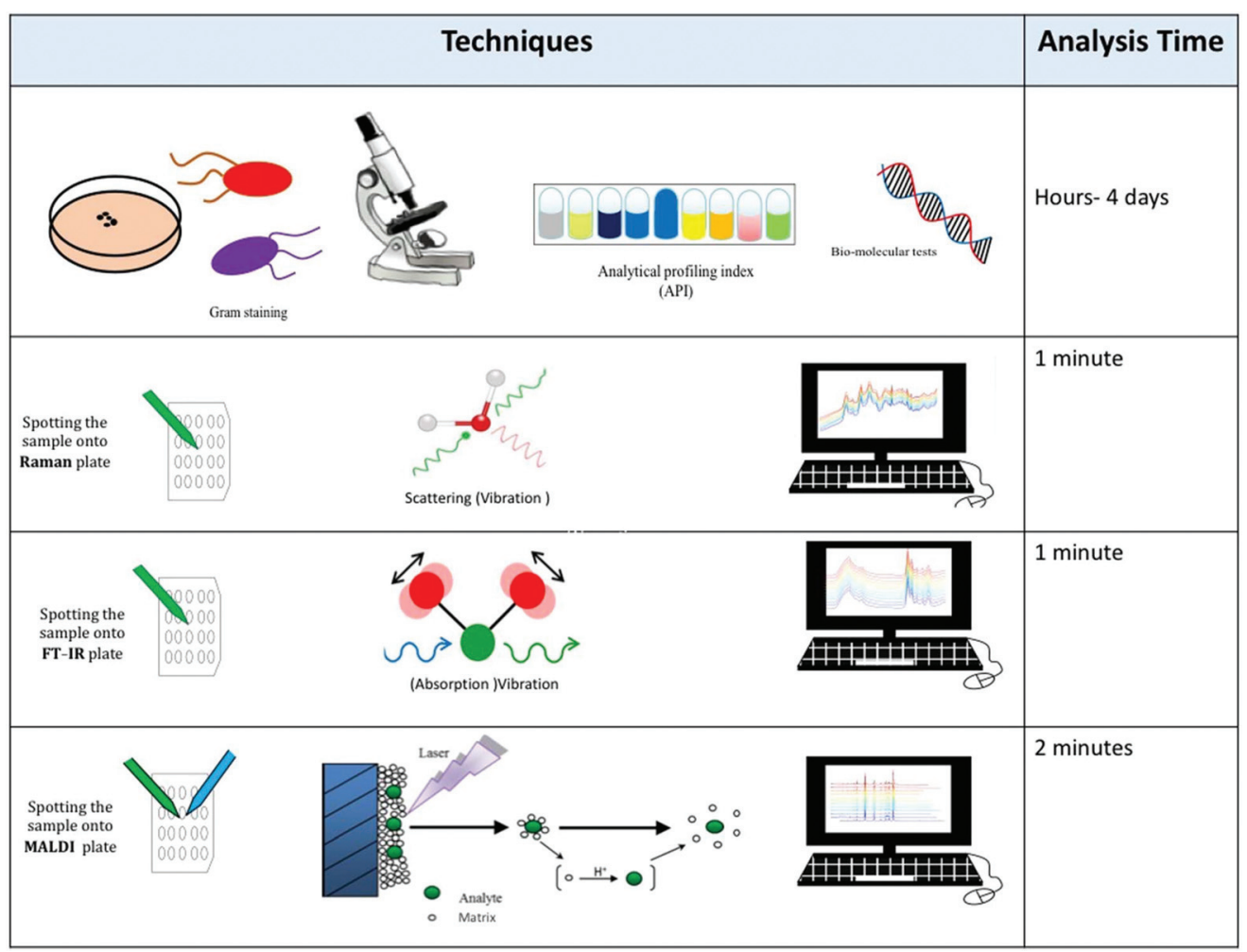

Fig. 2 Illustration of various methods used for bacterial characterisation, including traditional methods, vibrational spectroscopy, and MALDI-mass spectrometry.

identification, rather than routine old-fashioned traditional methods.

In this review, we discuss the use of mass spectrometric and vibrational spectroscopic methods as biomolecular analytical tools, with a specific focus on their application in identifying and classifying bacterial samples - a technique referred to as 'whole organism fingerprinting, ${ }^{17,18}$ Fig. 2 shows a schematic summary of the various methods used for bacterial characterization, including traditional methods, mass spectrometry and vibrational spectroscopy. It is noteworthy that MS, Raman spectroscopy and infrared spectroscopy probe the whole cell, which is in contrast to the traditional methods that target specific molecular species. Moreover, as these methods generate whole organism fingerprints, they measure the phenotype of the bacterial cell, which reflects the interaction of the microorganism's genotype within the environment it inhabits.

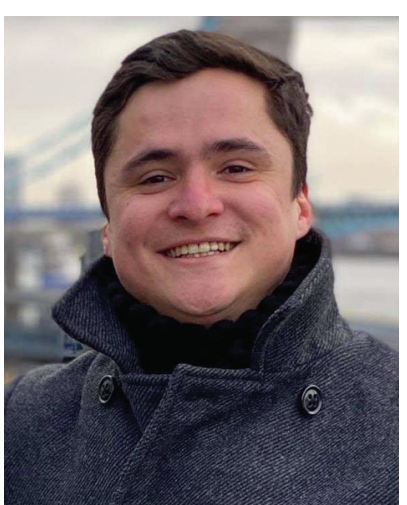

Cassio A. Lima
Cassio Lima obtained his B.Sc. in Physics from the Federal University of Uberlandia (Brazil) in 2013 and M.Sc. (2015) and PhD (2019) degrees from the University of Sao Paulo (Brazil). He joined Prof. Roy Goodacre's group at the University of Liverpool (UK) in 2019, where he currently works as a research associate. His main area of research involves characterisation of biological systems via vibrational spectroscopy including infrared (FTIR and O-PTIR) and Raman spectroscopy (classical Raman, CARS, SRS, and SERS).

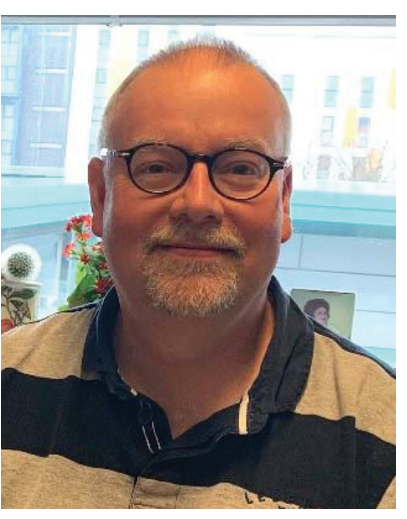

Royston Goodacre
Roy Goodacre is Professor of Biological Chemistry within ISMIB and director of the Centre for Metabolomics Research. He has extensive experience in mass spectrometry-based metabolomics and Raman and infrared spectroscopy, as well as advanced multivariate data analysis. Amongst other things he develops these physicochemical methods for bacterial typing. Full Bio: https://en.wikipedia. org/wiki/Roy_Goodacre. 


\section{Vibrational spectroscopic techniques}

Vibrational spectroscopy has attracted considerable interest over the past decades as a high-throughput screening technique for rapid analysis of various microbial and biological samples. ${ }^{19-21}$ FT-IR spectroscopy and Raman spectroscopy are the most popular vibrational spectroscopic platforms used for identification and classification of bacteria based on whole organism biomolecular fingerprints. ${ }^{22-24}$ Therefore, these spectroscopic techniques provide compelling evidence and useful data for investigating the intrinsic biochemical composition and variations in the bacterial phenotype. ${ }^{25}$ Interestingly, the spectral data and information obtained from these vibrational techniques contain a wealth of useful biochemical information from the whole cell and can be employed to identify, discriminate and characterise different bacterial species, including clinically and industrially relevant strains. ${ }^{26-28}$ In addition, these spectroscopic methods can be used to quantify the levels of biological products in microbial fermentations ${ }^{29}$ or small molecule biomarkers (e.g.) dipicolinic acid for quantification of bacterial spores. ${ }^{30,31}$

\section{Fourier-transform infrared spectroscopy}

An introduction to FT-IR spectroscopy for the microbiologist. FT-IR spectroscopy is a versatile analytical tool which is widely utilised for food quality control and pharmaceutical and medical research, in addition to bacterial classification and identification. ${ }^{32-35}$ FT-IR spectroscopy allows for rapid and high-throughput analysis without being destructive to bacterial samples. ${ }^{12,36} \mathrm{~A}$ wide range of research studies have indicated the application of FT-IR spectroscopy in combination with chemometrics to discriminate between different types of bacteria obtained from various sources, such as dietary and clinical products. ${ }^{37,38}$

In principle, FT-IR spectroscopy is based on the fundamental premise that when infrared light interacts with an investigated sample, there may be an increase in the amplitude of the vibrations of molecules such as stretching and bending vibrations as a result of absorption of this infrared radiation. ${ }^{28,39}$ The resultant vibrational modes of various molecular bonds are detected and measured simultaneously and can be directly matched to the biochemical species that give rise to them; hence, a precise fingerprint of infrared-active biomolecules is presented by peak intensities and wavenumbers (units of $\mathrm{cm}^{-1}$ and being defined as $1 / \lambda$ of the absorbing IR, which for mid-IR is 2.5 to $25 \mu \mathrm{m}$ ) in the infrared spectrum. The peak intensities provide quantitative information about the amounts of detected biochemical molecules whilst peak positions (wavenumbers) provide qualitative measurements related to the identity of investigated bacteria. It is also worth mentioning that for a molecule to absorb IR radiation, its molecular bonds should undergo a change in the permanent dipole moment as they vibrate at higher frequency. This implies that many polar biochemical bonds (e.g., $\mathrm{C}=\mathrm{O}, \mathrm{C}-\mathrm{N}$, $\mathrm{N}-\mathrm{H}$, etc.) present in proteins and peptides, carbohydrates, and fatty acids/lipids are frequently detected by FT-IR spec- troscopy. In bacterial classification and identification, most analyses of bacterial samples have been reported to fall within the mid-IR region (4000 to $600 \mathrm{~cm}^{-1}$ ) mainly because absorption patterns of functional groups in biological molecules are observed in this particular region as sharp fundamental vibrations, rather than broad overtones or harmonics which are found in the near-IR. In relation to applications and to facilitate unambiguous spectral band assignments of biologically relevant compounds, the mid-IR region is further divided into sub-regions that represent: ${ }^{36,40,41}$

(1) Fatty acids (3050-2800 $\left.\mathrm{cm}^{-1}\right): \mathrm{CH}_{2}$ and $\mathrm{CH}_{3}$ stretching vibrations,

(2) Proteins and peptides $\left(1750-1500 \mathrm{~cm}^{-1}\right): \mathrm{C}=\mathrm{O}, \mathrm{C}-\mathrm{N}$ and $\mathrm{N}-\mathrm{H}$, vibrations and

(3) Polysaccharides $\left(1200-900 \mathrm{~cm}^{-1}\right)$ : $\mathrm{C}-\mathrm{O}$ and $\mathrm{C}-\mathrm{O}-\mathrm{C}$ vibrational modes.

A growing resurgence of interest in the application of IR spectroscopy emerged in 1991 when Naumann and colleagues utilised this technique for analysing microbiological samples. ${ }^{42}$ Following this breakthrough, the past four decades have witnessed an exponential increase in the published literature which is clear evidence of the crucial role that the FT-IR technique plays in microbial analysis. Interestingly, FT-IR spectroscopy achieves successful discrimination between various taxonomic levels, growth conditions, ${ }^{43}$ detection of contaminants and prediction of antibiotic resistance as demonstrated by several researchers performing bacterial typing. ${ }^{44-46}$

FT-IR spectroscopy for bacterial typing. Application of the combination of FT-IR spectroscopy and chemometrics ${ }^{47,48}$ has been shown to enable accurate classification and identification of different clinical pathogens such as bacteria ${ }^{49,50}$ and fungi ${ }^{51,52}$ at different taxonomic levels. Lee and colleagues analysed four different strains of Pseudomonas spp., three different strains of Escherichia spp. and two different type strains of Bacillus spp. The results demonstrated clear discrimination between bacterial strains and the main differences were found to be in the frequency regions of amide I, amide II and $\mathrm{PO}_{2}{ }^{-}$ionised asymmetric and symmetric stretching, and this was confirmed by partial least squares discriminant analysis (PLS-DA) and hierarchical clustering analysis (HCA) of the FT-IR data. ${ }^{53}$ In another study, Rebuffo and colleagues applied an advanced multivariate analysis that involved the use of artificial neural networks (ANN) to identify Listeria at species levels. Analysis of FT-IR spectral data showed that 277 isolates from five Listeria species could be differentiated with $96 \%$ accuracy within $25 \mathrm{~h}$. These findings suggest that this technique is potentially suitable for routine analysis of foodborne pathogens in the laboratory. ${ }^{54}$ Another investigation carried out by Janbu et al. ${ }^{55}$ involved rapid analysis of five Listeria species using FT-IR micro- and macro-spectroscopy combined with chemometric techniques based on canonical discriminant analysis (CDA) and PLS-DA. Interestingly, the results obtained demonstrated a discrimination accuracy of $93 \%$ and $100 \%$ of all the screened species for FT-IR micro- and macrospectroscopic techniques respectively. It is very clear in this study that despite using smaller biomass (from microcolonies 
with dimensions 250-300 $\mu \mathrm{m}$ ), FT-IR micro-spectroscopy was capable of differentiating Listeria species accurately. This is very important in modern clinical and environmental microbiology where there is a shift towards microbial colony and single cell (with the emergence of nano-IR) level analyses for unequivocal identification, differentiation and characterisation of clinical pathogens even below the infective dose. The most recent study carried out by Wang et al. illustrated the ability of FT-IR to discriminate between 16 types of foodborne pathogenic bacterial strains, and was supported by multivariate analysis such as principal component analysis (PCA) and HCA of FT-IR data. In this study the authors found that a specific spectral region from 1300 to $1000 \mathrm{~cm}^{-1}$ which corresponds to phosphate and polysaccharide vibrations was successfully employed to discriminate bacterial strains. ${ }^{56}$

In other studies, Shapaval et al. ${ }^{57}$ developed a micro-cultivation protocol for FT-IR spectroscopy to identify various species of molds based on the spectral libraries combined with ANN models, resulting in an identification accuracy of $95 \%$ at the genus and species levels. Furthermore, Shapaval and coworkers ${ }^{58}$ established a library-independent method based on FT-IR spectroscopy and samples were accurately identified (from $80 \%$ to $100 \%$ ) at the genus or species levels. In an attempt to demonstrate the applicability of FT-IR spectroscopy as a diagnostic tool in clinical setting, Maquelin et al. ${ }^{59}$ employed FT-IR and multivariate analysis to identify bacteria and yeast pathogens such as Staphylococcus aureus, Escherichia coli, Enterococcus spp., Pseudomonas aeruginosa, Streptococcus spp., and Candida spp., which are frequently detected in the bloodstream of hospitalised patients. According to LDA and ANN analyses of FT-IR spectral data, a clinically acceptable identification accuracy of $>98 \%$ was clearly demonstrated and compared favorably with standard phenotypic identification tools (API and Vitek systems) routinely applied in hospital laboratory setting. In the same study, ${ }^{59}$ FT-IR analysis exhibited far superior turnaround time (6-8 h) than standard microbiological tools that took $\sim 48 \mathrm{~h}$ to obtain identification results.

Gram-positive bacteria, such as those belonging to the Bacillus genera ${ }^{60}$ and Listeria species, ${ }^{61}$ show good discrimination using FT-IR techniques, with a number of investigations focusing particularly on discriminating between different species. Listeria species are implicated as causative pathogens of Listeriosis, a foodborne microbial infection which has recently gained notoriety in South Africa, where a significant number of victims died following ingestion of food predominantly contaminated with Listeria monocytogenes. ${ }^{62,63}$ There is no doubt that rapid identification and classification of Listeria species is very desirable to guide effective therapeutic strategies, and thus to reduce mortality rates. Similarly, the discrimination of Bacillus genus was first attempted by Lin et $a .^{64}$ and Beattie et al. ${ }^{65}$ Lin and colleagues analysed Bacillus cereus isolates using IR, which involved the identification and differentiation of ten $B$. cereus group isolates, including B. cereus, B. mycoides, and B. thuringiensis strains, five Bacillus spp. isolates and five non-Bacillus spp. Furthermore, two different types of media were used in this study to analyse these isolates. The results clearly indicated that speciesspecific peaks appeared between 1738 and $1740 \mathrm{~cm}^{-1}$ in the IR data for the $B$. cereus isolates. In addition, other distinctive peaks of various band shapes and sizes were observed between 1800 and $1500 \mathrm{~cm}^{-1}$ for the analysed bacterial isolates. The results suggest that FT-IR spectroscopy can indeed be useful for quick identification of species within the B. cereus group. To illustrate the capability of the FT-IR tool for microbial analysis further, Beattie and colleagues ${ }^{65}$ expanded the study conducted by Lin and coworkers ${ }^{64}$ where they probed a variety of Bacillus species this time including B. cereus, B. circulans, B. firmus, B. licheniformis, B. megaterium and B. pumilus. In this study, the FT-IR method was supported by canonical variate analysis (CVA) which proved to be effective in discriminating between different types of Bacillus bacteria with a success rate of $95 \%$. Other authors have also illustrated the ability of FT-IR spectroscopy coupled with robust chemometrics to discriminate between different infectious Listeria spp. ${ }^{66}$ lactic acid bacteria, ${ }^{67}$ Salmonella $^{68}$ and Pectobacterium and Dickeya spp. ${ }^{69}$ These studies clearly demonstrate that FT-IR spectroscopy is capable of classifying and differentiating between medically and industrially important bacteria and other microorganisms at various taxonomic levels, which are important prerequisites for appropriate patient management and protection of public health.

Although FT-IR spectroscopy does not provide detailed information regarding specific molecules due to the molecular complexity of biological samples, and the fact that the information provided in FT-IR spectra is related to functional groups, compared to some other techniques such as MALDI-MS, it is recognized as an important tool that can be employed for rapid screening of complex mixtures (e.g., bacterial samples) composed of small biomolecules and biopolymers such as proteins, carbohydrates, lipids, nucleic acids and amino acids ${ }^{70,71}$ with only a minimal amount of sample and sample preparation required.

One of the drawbacks of FT-IR spectroscopy is that it registers strong broad bands for water molecules in the mid-IR region which are likely to mask some vital diagnostic peaks which may potentially lead to misinterpretation of spectral data. This problem is usually overcome by drying the samples at appropriate temperatures, using heavy water $\left(\mathrm{D}_{2} \mathrm{O}\right)$, attempting to subtract $\mathrm{H}_{2} \mathrm{O}$ signals or using attenuated total reflectance (ATR) as a different IR sampling method. ${ }^{72}$ Another alternative to overcome these limitations is to employ Raman spectroscopy.

\section{Raman spectroscopy}

Introductory Raman spectroscopy for the microbiologist. Over the last decade, Raman spectroscopy has been used successfully as an alternative and complementary physicochemical analytical technique to FT-IR spectroscopy. Different microbial samples such as bacteria, yeast and fungi can be identified and differentiated at the species and subspecies levels. This is mainly because Raman spectroscopy has clearly demonstrated high accuracy, speed and spatial resolution for microbial analysis in the past decades. Another attribute that sets Raman 
spectroscopy apart from other microbial typing tools is that the Raman signals of water are very weak, making Raman spectroscopy more appropriate for detecting microbes directly within aqueous habitats in which microbes naturally reside. ${ }^{73,74}$

Like FT-IR spectroscopy, Raman spectroscopy is a nondestructive and portable technique, potentially enabling its application within or outside centralised clinical settings when analysing bacterial samples at the point of care - through so called 'point-and-shoot' analysis. ${ }^{75}$ Although Raman spectroscopy was traditionally used for analytical chemistry applications, there has recently been an increase in biological and pharmaceutical studies that utilise this technique. ${ }^{76-78}$ The fundamental principle behind Raman spectroscopy lies in its ability to use monochromatic light delivered by powerful lasers, mainly in the near-IR (NIR) to visible, or within UV regions, which exploits the Raman effect (inelastic scattering). The Raman scattering effect occurs in a very small fraction of scattered photons (relative to the Rayleigh process which is the dominant effect) after excitation of molecules. ${ }^{71}$ The Raman effect is caused when there is a difference between the energy of the scattered photon and the incident photon following interaction between the electric field of incident radiation and sample molecules being analysed. This interaction causes distortion of electron clouds in symmetrical Raman-active covalent chemical bond vibrations which results in increased induced dipole moment (polarizability). This scattering event causes energy exchange due to collisions between photons and molecules resulting in the molecules either gaining or losing a minimal amount of energy. An increase in molecular energy of sample molecules causes a decrease in the scattered photons resulting in Stokes scattering whereas the decrease in molecular energy due to the transfer of quantum energy to the scattered radiation leads to anti-Stokes scattering. In contrast, Rayleigh scattering (also known as elastic scattering) does not change the quantum state of the sample molecules under investigation significantly; that is to say it does not provide useful qualitative or quantitative information about the sample molecules. Despite being very useful, Raman scattering is an inherently weak effect since typically only about 1 in $10^{6}-$ $10^{8}$ photons scatter in an inelastic manner leading to lower sensitivity and longer spectral collection times. ${ }^{79}$
To overcome this weakness, a number of improved sample preparation methods and techniques are used in conjunction with Raman spectroscopy, including surface enhanced Raman scattering (SERS $)^{80-83}$ resonance Raman spectroscopy (RRS), ${ }^{84,85}$ coherent anti-Stokes Raman spectroscopy (CARS) ${ }^{86,87}$ and stimulated Raman spectroscopy (SRS) ${ }^{88}$ and are shown to enhance Raman signals by several orders of magnitude which is often needed for bacterial classification and identification.

The continuous development of instrumentation and computing has increased the popularity of Raman spectroscopy, thereby increasing the scope of application in bacterial classification and identification. Table 2 shows the main Raman bands that are seen in bacterial samples and their corresponding assignments. ${ }^{71,89,90}$

Raman spectroscopy for bacterial typing. Raman spectroscopy provides a high degree of flexibility for a number of applications in bacterial identification and classification, enabling data to be recorded and analysed for bacterial samples from a variety of biological sources, ${ }^{89}$ including directly from colonies. ${ }^{25}$ Advances in Raman spectroscopy enables the discrimination of intact bacteria without the need for complex sample preparation, providing reproducible and distinct biochemical fingerprints for each bacterial strain, ${ }^{91}$ and allowing reliable identification to be carried out.

Raman spectroscopy has been applied for the detection and characterisation of various microbes as well as assessment of the response of microbes to external perturbations. For example, Athamneh et al. ${ }^{92}$ demonstrated the ability of Raman spectroscopy to profile the phenotypic response and susceptibility testing of $E$. coli to antibiotics using $532 \mathrm{~nm}$ excitation laser wavelength. In this study, E. coli cultures were subjected to 15 different antibiotics (including amongst others ciprofloxacin, ampicillin, and kanamycin) with known mechanisms of action for 30 min. The results showed that Raman spectra contained promising biochemical information to differentiate between profiles induced by individual antibiotics belonging to the same class. Other researchers used UV resonance Raman spectroscopy for the characterisation of bacteria, ${ }^{93}$ and went on to demonstrate that when bacteria were challenged with different concentrations of the antibiotic amikacin, which

Table 2 Main peaks that are observed in Raman spectra from bacteria, along with their corresponding assignments

\begin{tabular}{ll}
\hline Peak wavenumber $\left(\mathrm{cm}^{-1}\right)$ & Band assignment \\
\hline$\sim 3064$ & $=\mathrm{C}-\mathrm{H}$ stretching in proteins, lipids, etc. \\
$2800-3100$ & $\mathrm{CH}_{3}$ and $\mathrm{CH}_{2}$ stretching from lipids, carbohydrates, proteins, etc. \\
$\sim 1655$ & $\mathrm{C}=\mathrm{O}$ stretching from amide I \\
$1575-1590$ & Ring vibrations in guanine and adenine \\
$\sim 1550$ & $\mathrm{~N}-\mathrm{H}$ bending and $\mathrm{C}-\mathrm{N}$ stretching in amide II (weaker than amide I and III) \\
1453 & $\mathrm{CH}_{2}$ deformations in proteins, lipids, etc. \\
1339 & Adenine, guanine, tyrosine ring vibrations \\
$1230-1295$ & $\mathrm{C}-\mathrm{N}$ stretch and $\mathrm{N}-\mathrm{H}$ bend in amide III \\
$\sim 1170$ & Tyrosine, phenylalanine vibrations \\
$\sim 1002$ & Ring vibrations in phenylalanine \\
$\sim 1087$ & C-O stretching from amides, proteins or $\mathrm{P}=\mathrm{O}$ stretching in phosphodiesters, flavin adenine dinucleotide, etc. \\
$\sim 781$ & Cytosine, uracil (ring stretching)
\end{tabular}


inhibits protein synthesis, quantitative changes could be seen in the protein and nucleic acid vibrations when excitation was in the deep UV at $244 \mathrm{~nm} .{ }^{94}$ Another study was carried out by Zhou et $a .^{95}$ in which the authors illustrated the utility of novel nanostructures, AgNPs coating bacteria structure, for quick counting and differentiation of live and dead bacteria via SERS. Furthermore, Kusić et al. ${ }^{96}$ used Raman micro-spectroscopy (that is to say, Raman technique coupled with a microscope) in combination with support vector machines (SVMs) to identify water pathogens at the single cell level. The authors further illustrated that Raman spectroscopy can be employed as a fast and reliable technique to discriminate between Legionella species and to identify unknown samples.

Assaf at el. ${ }^{97}$ distinguished between two closely related species, Salmonella enterica and E. coli, inoculated and examined with six of the most frequently used buffered peptone water brands using Raman spectroscopy. The results illustrated that bacterial cells behaved inversely depending on the water brand used in terms of biomass production and the spectral fingerprint. The accuracy of the analysed bacteria was achieved between $85 \%$ and $100 \%$, and this was similar to the findings of another study conducted by Wang et al. ${ }^{98}$ where the detection of pathogenic $S$. aureus was successfully reported using Raman spectroscopy. In another study, the successful classification of six bacterial species (B. cereus, Enterobacter aerogenes, E. coli, Streptococcus pyrogenes, Enterococcus faecalis and Streptococcus salivarius) was carried out by Xie et al. using Raman spectroscopy. ${ }^{99}$ In addition, Harz et al. ${ }^{100}$ reported the successful discrimination of several Staphylococcus species both at the species and strain levels. A further study carried out by Schmilovitch et al. ${ }^{101}$ enabled clear distinction between Gram-positive and Gram-negative bacteria using Raman spectroscopy with a diode laser of $785 \mathrm{~nm}$ excitation. These examples provide evidence that Raman spectroscopy can be used for the analysis of bacterial samples using various sample preparation methods, instrumentation parameters and chemometric tools.

Although Raman spectroscopy exhibits poor quantum efficiency in comparison with IR spectroscopic techniques, SERS is often employed to enhance Raman signals, resulting in increased sensitivity down to single molecule detection. ${ }^{102}$ SERS involves the measurement of the interactions between plasmonic metallic nanoparticles (NPs) and sample molecules; these molecules can be in direct contact to or reside in close proximity to the NP surface. ${ }^{103,104}$ Although the SERS enhancement mechanisms are still inconclusive, and that the debate is still ongoing within the SERS community, ${ }^{105}$ the enhancement of the Raman scattering observed via the SERS method is largely due to the incident excitation frequency being resonant with the surface plasmon resonance in metallic nanostructures, the so-called localised surface plasmon resonance (LSPR). Silver (Ag) and gold (Au) based colloidal NPs are most widely used as enhancement substrates due to their low cost, ease of synthesis and high stability under normal laboratory condition. For more detailed description of SERS principles, readers are directed to the following excellent reviews. ${ }^{104,106,107}$
The first demonstration of SERS for the identification of bacteria was reported by Jarvis \& Goodacre, who showed that the signal arose from the surface features of the cell due to the interaction of the LSPR with the bacterial cell surface. ${ }^{108}$ Some bacteria can naturally reduce $\mathrm{Ag}$ (I) and $\mathrm{Au}(\mathrm{III})$ to $\mathrm{Ag}$ and $\mathrm{Au}$ NPs, respectively and thus the signal can be made to arise from within bacterial cells. ${ }^{109}$ This so-called in situ production of $\mathrm{Ag}$ or $\mathrm{Au} \mathrm{NPs}$, where metallic particles are formed in the presence of bacterial cells and attached to either the cell surface or cytoplasmic biomolecules, was recently employed to differentiate among five near isogenic cell wall mutants of a single strain of Campylobacter jejuni foodborne pathogen. ${ }^{80}$ Interestingly, the SERS findings were consistent with the results obtained from Raman spectroscopy and matrix-assisted laser desorption/ionisation mass spectrometry data applied as confirmatory techniques in this study, clearly demonstrating excellent reproducibility and robustness of SERS. It is thus clear that due to the plasmonic enhancement effect it is not surprising that SERS is a highly sensitive, fast and reliable analytical tool that can detect low concentration of bacterial cells, differentiate closely related pathogens and more importantly can probe single prokaryotic cells and highly infectious biowarfare agents. ${ }^{104}$ This makes SERS very attractive and useful in clinical diagnostics, food and water quality and safety control measurements where rapid, sensitive and unequivocal detection of infectious pathogens is absolutely important. ${ }^{110}$

All the above studies analysed the whole organism. By contrast, a recent study carried out by Kearns et al. ${ }^{111}$ developed a new bionanosenser to detect specific bacterial pathogens (E. coli, Salmonella typhimurium, and methicillin-resistant $S$. aureus) simultaneously by SERS that was targeted to specific DNA sequences. This enabled the authors to multiplex the pathogen detection, and was shown to be highly quantitative when multivariate analyses were made. For information on quantification of analytes and bacteria by SERS the reader is direct to these recent reviews. ${ }^{83,104,112}$

Finally, perhaps the most exciting aspect of Raman spectroscopy is that it is possible to measure single bacteria. This is because the excitation source used for Raman spectroscopy is a UV to near IR laser that is highly focused and thus possesses similar dimensions to bacterial cells $(c a .1 \mu \mathrm{m})$. Schuster and colleagues were perhaps the first to demonstrate that Raman spectroscopy had sufficient spatial resolution and generated chemical information about single cells of the industrially-relevant Clostridium beijerinckii. ${ }^{113}$ Single cell analysis has been demonstrated by several groups, including for measuring metabolic activity of cells, ${ }^{28,103}$ and opens up the tantalising realisation that bacteria could be analysed without the need for a culture step. ${ }^{114}$ Thus Raman spectroscopy would appear to possess this major advantage over infrared spectroscopy. However, with the recent developments of atomic force microscopy-infrared (AFM-IR) ${ }^{115}$ and optical photothermal infrared (O-PTIR) spectroscopy, ${ }^{116}$ infrared microspectroscopy is starting to rival Raman spectroscopy for analysis of single bacterial cells. By way of example Fig. 3 shows an infrared spectrum collected using O-PTIR from a 

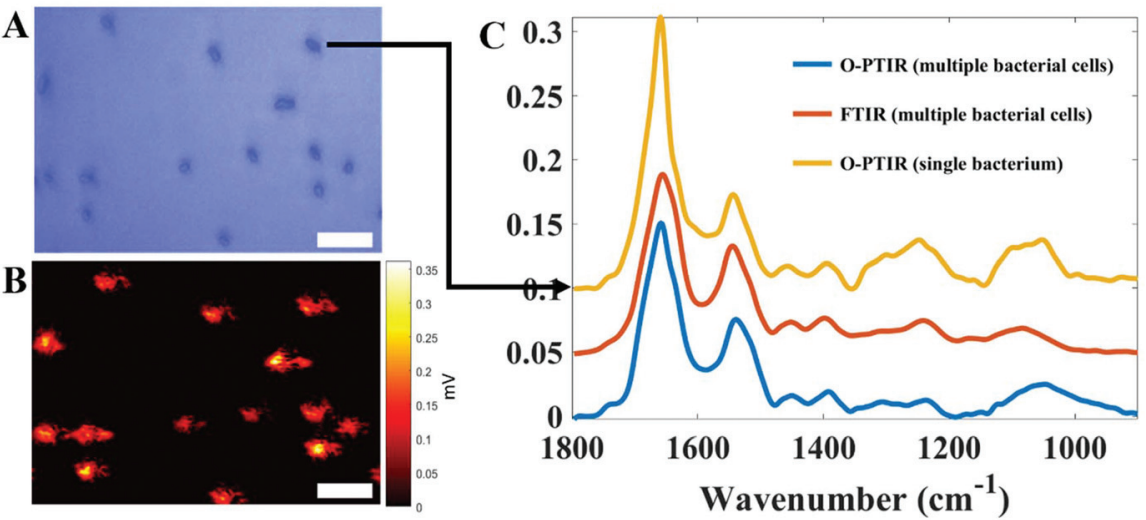

Fig. 3 Infrared spectral signatures acquired from E. coli cells via O-PTIR using a mIRage infrared microscope from Photothermal Spectroscopy Corp and FT-IR spectroscopy operating in transmission mode on a Bruker Equinox 55 infrared spectrometer. (A) Optical image displaying several E. coli cells. (B) Single frequency image obtained through O-PTIR imaging for the amide I band $\left(1655 \mathrm{~cm}^{-1}\right)$. (C) Infrared spectra acquired from single E. coli cells via O-PTIR (yellow line) as well as from multiple bacterial cells (bulk) of the same strain using traditional FT-IR (red line) and O-PTIR (blue line) technologies. In A and B, the scale bar is $3 \mu \mathrm{m}$.

single $E$. coli cell with typical dimensions of $1 \times 2 \mu \mathrm{m}$ weighing just $1 \mathrm{pg}$.

\section{Mass spectrometry}

Mass spectrometry (MS) is regularly used in biological studies for qualitative and quantitative purposes. This analytical technique exploits the use of a core physical property, the mass-tocharge ratio $(\mathrm{m} / \mathrm{z})$ of molecules as well as their fragmentation patterns that can be used for analyte identification. Prior to the use of this analytical technique, conventional methods were employed for detection of biomolecules in bacterial samples based on direct chemical or electron ionisation techniques ${ }^{117}$ or through the use of pyrolysis as a sample introduction technique. ${ }^{118,119}$ The main disadvantages of these conventional techniques were that the energy associated with their operation caused considerable decomposition of samples, which led to very complex and often uninterpretable mass spectra. Thus, conventional methods were gradually replaced by more advanced hyphenated mass spectrometric methods. Gas chromatography in combination with mass spectrometry (GC-MS) is one such example of common hyphenated techniques that can be used to analyse volatile and nonvolatile (after sample derivatisation) small molecules both qualitatively and quantitatively; ${ }^{120}$ however, the use of chromatography necessitates relatively long analysis times (30-60 min is typical) and complex deconvolution steps are involved, thus making GC-MS both time-consuming and laborious, and the same can be said for liquid chromatographymass spectrometry (LC-MS). ${ }^{121}$ This highlights the need for other more rapid and facile methods of analysis. The introduction of soft ionisation techniques such as matrix-assisted laser desorption/ionisation (MALDI) ${ }^{122}$ and electrospray ionisation $(\mathrm{ESI})^{123}$ in the late 1980s solved the problems associated with harsh ionisation techniques. Many MS methods have since been developed for use in a wide range of applications, such as biological, chemical and life sciences. MALDI and ESI are highly accurate methods that have been employed for the identification and characterisation of proteins, lipids, sugars and nucleic acids in various biological samples, and as such are ideal for the analysis of bacteria. ${ }^{124}$ Whilst some researchers have developed ESI-MS via direct infusion for bacterial classification, ${ }^{125,126}$ the vast majority of mass spectrometrybased bacterial identification has been undertaken using MALDI-MS.

\section{An introduction to matrix-assisted laser desorption/ionisation mass spectrometry}

Although FT-IR spectroscopy and Raman spectroscopy are regarded as powerful physicochemical tools, the introduction of MALDI-MS proved to be a preeminent advancement in the identification of bacteria within clinical microbiology laboratories due to the speed, accuracy, simplicity and cost-effectiveness of this technique. ${ }^{127}$

MALDI-MS works by producing molecular ions when a laser beam is applied to analytes, which are mixed prior to analysis with a matrix, and air dried. Analyte and matrix mixtures are analysed on a MALDI target metal plate with the most common ones being stainless steel, aluminium and gold. ${ }^{128}$ The matrix is a highly concentrated solution of low molecular weight, generally acidic, organic molecules that contain a conjugated double bond system capable of absorbing the UV laser energy used in MALDI. ${ }^{129}$ Examples of matrices that absorb in the UV (337 nm excitation is typical of MALDI) include sinapinic acid (SA), ${ }^{130} \alpha$-cyano-4-hydroxycinnamic acid (HCCA ${ }^{131,132}$ and 2,5-dihydroxybenzoic acid (DHB). ${ }^{133,134}$ There is no universal matrix or a standard method for the deposition of the analyte/matrix mixture on the MALDI plate that can be used for routine analysis, nor a set of guidelines in the literature to assist in choosing the optimal matrix and protocol for the analysis of microorganisms and other sample analytes. Hence, the 
matrix and preparation method most suitable for a particular application are typically chosen on the basis of trial and error, although some researchers have used the design of experiments to optimise the matrix and preparation method, ${ }^{135}$ that can be applied for bacterial characterisation. ${ }^{136}$ The suitability of the matrix used in any research study is highly dependent on certain factors, including the solubility of the matrix in different solvents and its ability to absorb laser energy at the wavelength used in the MALDI-MS device. In MALDI-MS, sample and matrix molecules co-crystallize on the plate and subsequently different types of laser beams, with the most popular being in the UV with a nitrogen laser $(337 \mathrm{~nm})$ or sometimes in the infrared with an erbium doped yttrium aluminium garnet (Er:YAG) laser (2940 nm), can be used to excite the analyte/matrix crystals. Irradiation of the analyte/matrix system by a laser pulse leads to desorption of the embedded analyte molecules. ${ }^{131}$ The mechanism of desorption is not well-understood and the desorbed molecules are ionised forming predominantly singly charged ions, which are separated and counted by the time-of-flight (TOF) mass analyser. ${ }^{4}$

MALDI, being a very soft ionisation technique, also allows the direct measurements of proteins in whole bacterial cells, without any fragmentation. ${ }^{137,138}$ In these methods, the majority of proteins that can be identified are ribosomal proteins, which are detected quite easily due to their smaller size and high abundance. Moreover, the fact that amino acid sequences of ribosomal proteins are conserved to a great extent at the genus and sometimes at the species level, the slight variations in these sequences can be used to distinguish bacteria at the strain level. ${ }^{139}$ One of the benefits of the ribosomes being measured is that they are always produced under any growth condition and so are not susceptible to variable phenotypic effects during bacterial cultivation; this may be why the method is very stable and used routinely in many clinical microbiology laboratories. Identification of bacteria at the genus, species or strain level is usually performed using the obtained protein mass patterns together with a library based approach or a bioinformatics enabled analysis. ${ }^{140}$ In both of these methods, the analyst is comparing and matching distinguished and discriminated peak (biomarker) in the MALDI-MS profiles of the bacteria under investigation with publicly available databases. ${ }^{141,142}$

The use of MALDI-MS has been extended to a variety of research areas, including the direct analysis of organisms and biological tissue samples and the characterisation of peptide and protein components. ${ }^{143-145}$ In addition to its qualitative applications, MALDI-MS is also a popular quantitative tool due to its ability to analyse molecules over a wide range of mass, its high sensitivity, easy and fast sample preparation, and short analysis time. Quantification can be relative to a reference sample or based on the use of internal isotopically labelled standards. Challenging samples have been successfully characterised and quantified using MALDI-MS, including intact peptides and proteins measured directly in biological tissues and fluids. ${ }^{4}$

Despite the numerous reported quantitative MALDI-MS applications, there still remain some limitations that restrict the widespread use of MALDI-MS and these are thought to be mainly associated with analyte/matrix mixture heterogeneity, which results in variable analyte signal intensities. Other limitations include the difficulty in coupling MALDI-MS to separation techniques, such as liquid chromatography, and limitations of the dynamic range that arise due to saturation of the detector. Together, these factors most likely compromise the use and reliability of making quantitative determinations using MALDI-MS, with the majority of studies focusing on analytes of low molecular mass, for example food products, ${ }^{146}$ while other investigations utilised MALDI-MS as a relatively quantitative tool in biological applications, such as the analysis of proteins, ${ }^{147}$ neuropeptides, ${ }^{148}$ antibiotics, ${ }^{149}$ and metabolites in biological tissues or fluids. ${ }^{150}$

\section{Bacterial typing with MALDI-MS}

Drucker and Fenselau were the first to report the typing of microbes using MALDI-MS in 1993, where the identification of microbial samples was based on their cellular lipid compositions. Since then, the identification of microbes has developed so that they can be identified based on their protein profiles, which can be directly obtained from whole cell organisms ${ }^{151}$ with the first application of rapid identification of bacteria from protein profiles reported by Claydon and coworkers in 1996, ${ }^{152}$ which was closely followed by very similar findings by another research group later the same year. ${ }^{153}$ Since 2016, Korea has introduced the use of MALDI-MS as a new clinical analytical technique in healthcare for reliable routine analysis. This has the potential to identify bacterial infections correctly, leading to timely prescription of appropriate antibiotics to treat infections effectively and limit resistance. Lange et al. analysed different types of bacteria (108 Klebsiella spp. isolates) using MALDI-MS in the presence of meropenem; in this work a sensitivity and specificity of $97 \%$ and $94 \%$ respectively were achieved. ${ }^{154}$ A recent study was carried out by Axelsson et al. where the authors showed the ability of MALDI to distinguish between susceptible and resistant strains of $E$. coli and $K$. pneumoniae with 90 min of incubation at $37^{\circ} \mathrm{C}$ for three different types of antibiotics (cefotaxime, meropenem and ciprofloxacin). In this study, overall 841 positive blood culture analyses of 14 reference strains were achieved, and the results showed high sensitivity (99\%), specificity (99\%) and accuracy (97\%). ${ }^{155}$ DeMarco et al. demonstrated clear detection and identification of bacteria directly from urine samples without the need for bacterial culture steps, using the diafiltration MALDI-MS technique. ${ }^{156}$ Similarly, Nakano et al. carried out a study using MALDI-MS to discriminate between 10 major serotypes of $S$. pneumoniae. ${ }^{157}$ Woods et al. went further to differentiate a large number of $S$. anginosus group using MALDI-MS with a high sensitivity of 93\%. ${ }^{158}$ Moreover, discrimination between 35 Enterococcus faecium strains was carried out in clinical samples using MALDI-MS at the strain level with high accuracy (78\%). ${ }^{159}$ Finally in a recent study Zhu and co-workers showed that bacteria isolated from blood culture could be identified from as 
little as 500 cells per $\mathrm{mL}$ in blood serum and 8000 cells per mL in whole blood. ${ }^{160}$

As MALDI-MS currently dominates clinical microbiology labs for bacterial typing, and in some areas replacing traditional microbiological methods for bacterial typing, we discuss the methods that people have used to conduct MALDI-MS on bacteria for bacterial characterisation and identification.

\section{MALDI-MS: sample preparation for bacterial analyses}

Researchers have assessed several MALDI-MS sample preparation methods for many different microorganisms. Whilst direct cell profiling can be used to identify some microbes, some researchers have developed methods for the generation of whole cell lysates or crude cell extracts. When using direct cell profiling, a single bacterial colony can be gathered using a plastic loop and placed onto a MALDI sample plate, which is then overlaid directly with the matrix solution (see below for a discussion of common matrices used) before analysis. MALDI-MS of intact bacteria has been used to identify Gramnegative bacteria, such as Neisseria spp. ${ }^{161}$ and Vibrio spp. ${ }^{162}$ By contrast, as the cell wall of Gram-positive species is tougher 'preparatory extraction' of microbes with formic acid (FA) is preferred for bacterial identification. However, Gram-negative bacteria cannot be identified using this extraction method. ${ }^{163,164}$

Aerobic actinomycetes such as Nocardia and Mycobacterium species require specialized processing procedures prior to the MALDI-TOF analysis due to the composition of their cell walls which contain mycolic acids. Verroken et al. ${ }^{165}$ developed a modified procedure for the identification of Nocardia spp. by MALDI-MS, in which bacteria are first lysed in boiling water and the proteins are then precipitated using ethanol. The proteins are dried and resuspended in 70\% FA and acetonitrile (ACN). This was followed by analysis using MALDI-MS. Several different procedures have been reported regarding sample preparation protocols used for the identification of mycobacteria by MALDI-MS; some of these examples include direct bacterial profiling and treatments using formic acid. However, due to the pathogenicity of some Mycobacterium spp. safety issues have been a concern during investigations. A procedure that combined both bacterial inactivation and process methods was described by El Khéchine et al. ${ }^{166}$ Colonies from mycobacteria were collected using screw-cap tubes, with water and $0.5 \%$ Tween 20 , which were then inactivated by heating for $1 \mathrm{~h}$ at $95^{\circ} \mathrm{C}$. The inactivated samples were then subjected to centrifugation and then vortexed with glass beads, which led to the disruption of the mycobacterial cell wall. The resultant pellet was resuspended in FA and followed by centrifugation. Finally, the supernatant was spotted onto the MALDI plate and was overlaid with a suitable matrix. ${ }^{166}$

\section{MALDI-MS: choosing the best matrix}

It can be challenging to choose the most suitable matrix for the analysis of specific bacteria. This is because there are currently no agreed guidelines documented (so called Standard
Operating Procedures (SOPs)) to assist the process of choosing the most suitable matrix and deposition protocol for the analysis of all possible microorganisms. Thus, the matrix is generally chosen through trial and error. The matrix used is usually determined by looking at a number of different factors, including the solubility of the matrix in different solvents, as well as its ability for enhanced desorption and ionisation by having the correct laser excitation frequency. An appropriate matrix selection is a vital phase in the development of the sample preparation protocol for the MALDI-MS and the preferred matrices for direct analysis of bacteria for proteins include CHCA, SA, DHB, with the addition of FA. On the other hand, with lipid or phospholipid ionisation, 2-mercaptobenzothiazole (MBT) or CMBT is favoured. ${ }^{167}$ Unfortunately, there is no agreement on what the best matrix for the MALDI-MS bacteria profiling is, because of the various factors that contribute to the ionisation process and thus the MALDI-MS profile quality. These include the variability of sample preparation procedures and the analyte itself, the chemicals used, etc. It has been found that when using a different matrix for the same type of bacteria, a substantial change occurs in the MALDI mass spectrum. For example, Demirev et al. ${ }^{168}$ noted that CHCA generated very different signals from the SA/4-methoxycinnamic acid (MCA) mixture when used for $E$. coli cells.

The use of alpha-cyano-4-hydroxycinnamic acid (CHCA) has been reported in nearly half of the studies in the field of MALDI bacteria profiling for analysis of peptides or small proteins. CHCA is generally chosen instead of other matrices, due to its high detection rate, signal intensity in the lower mass range ${ }^{169-171}$ and its sensitivity. ${ }^{172}$ It was concluded that a higher frequency of signals resulted in the formation of doubly protonated ions. ${ }^{173}$ Despite the numerous advantages that CHCA has to offer in MALDI-MS, there are also a number of disadvantages, such as its lower signal resolution in comparison with FA and SA, it has a higher degree of peak broadening and the lack of signals in the high-mass range, compared to FA. ${ }^{174}$

SA is another well-known protein matrix, which has also been widely used in studies carried out on bacteria profiling using MALDI-MS. Many studies reported better ionisation of high molecular weight proteins, ${ }^{175}$ in turn benefiting from less frequent peak broadenings, improved spectral quality, sample homogeneity, greater mass accuracy, and shot-to-shot reproducibility, as well as better signal resolution. This matrix has also been found to have the best signal-to-noise ratio and signal intensity among other matrices. ${ }^{176-178}$ Furthermore, other researchers preferred the use of FA as the matrix for bacteria profiling, because of its ability to ionize compounds with higher molecular weight, ${ }^{179}$ its good signal resolution and shot-to-shot reproducibility.

As there are many matrices to choose from, some researchers have decided to use combinations of matrices for bacterial analysis. A binary 1:1 mixture of 2-(4-hydroxyphenylazo) benzoic acid (HABA)/MBT was found to produce peaks in the high mass range from extracted proteinaceous materials extracted from $E$. coli. ${ }^{180}$ 
Finally, choosing an appropriate solvent is another vital step for sample preparation prior to analysing samples using MALDI-MS. Solvent volatility is frequently modified to attain large biomolecule ionisation; this is because slow crystallisation is thought to generate larger matrix crystals. Alternatively, the homogeneity of the matrix layer is composed of small crystals through fast solvent evaporation, enhancing shot-to-shot reproducibility. Conway et al. ${ }^{181}$ described that the SA matrix dissolved in $30 \%$ ACN $(0.1 \%$ TFA $)$ and mixed with an Enterobacteriaceae suspension in water led to a wider range and higher signal intensity in comparison with when samples were dissolved in isopropyl alcohol. Moreover, Ruelle et al. ${ }^{182}$ stated that CHCA dissolved in $0.1 \%$ TFA/ACN $(60: 40)$ resulted in the formation of peaks from $E$. coli suspension only in the low-mass region, while additional peaks in the high-mass range were detected when dissolved in ACN/isopropanol/0.1\% TFA.
As is clear from the above there is still much room for development in the best matrix and solvent combinations to use for MALDI-MS analysis of intact bacteria as well as solvent extracts for peptide, protein or lipid analysis.

\section{MALDI-MS: sample deposition approaches}

Several sample deposition methods can be used for MALDI-MS analysis. When the matrix and analyte are homogenized, cocrystallisation occurs, prompting the formation of sweet or hot spots. The methods for sample deposition are generally easy to perform. The most frequently used ones for sample preparation are mixing the bacteria and matrix together, overlay, underlay and sandwich methods. These methods are illustrated within Fig. 4.

Vaidyanathan et al. ${ }^{178}$ analysed B. sphaericus, E. coli, and Brucella laterosporus and observed difference in low- and high-

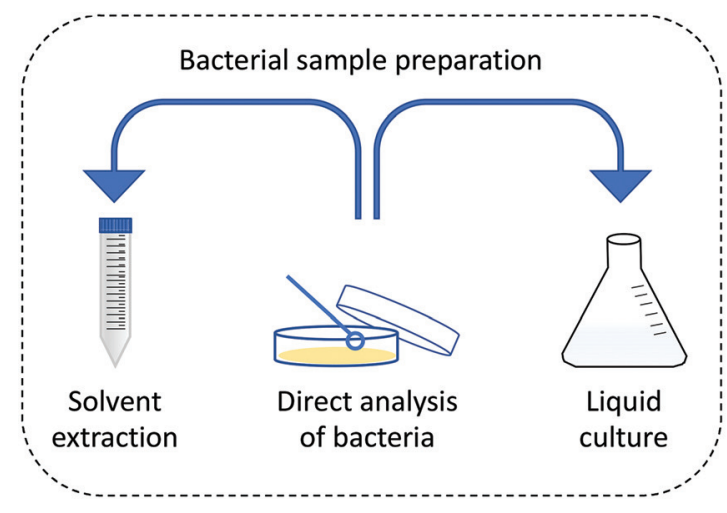

\section{Microbiological question:}

Typing to species level
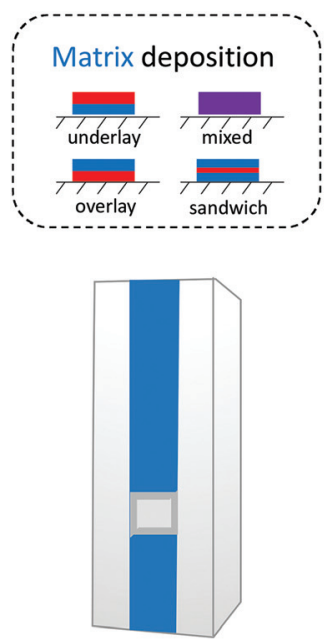

MALDI-MS
Species/sub-species typing Phenotypic characterisation

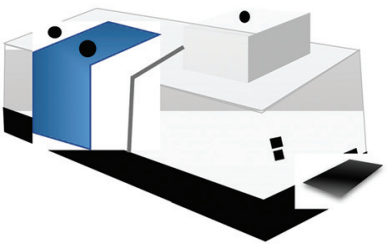

FT-IR spectroscopy

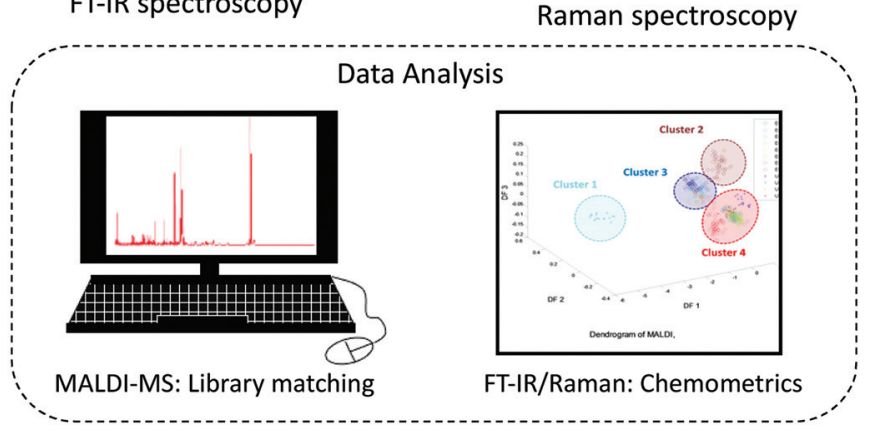

Fig. 4 Generalised scheme showing the role of MALDI-MS, FT-IR and Raman spectroscopy for addressing four different microbiological roles. Also shown are the main bacterial sample preparation methods, along with matrix deposition approaches for MALDI-MS (blue represents the UV absorbing matrix and red the bacteria), as well as the need for robust multivariate analysis. 
mass ranges of MALDI-MS profiles when three separate sample deposition methods were investigated. These included:

(a) Mixed method - a pre-mix of the bacterial suspension with the matrix solution was used,

(b) Modified underlay method - where the matrix was first spotted on a MALDI plate, then a pre-mix of sample/matrix was added as an additional layer,

(c) Overlay method - where the bacterial sample was first spotted on a MALDI plate, allowed to dry, and was then covered with the matrix solution.

The last approach provided the best spectra in terms of the number of detected signals and signal-to-noise ratio. Despite this finding other workers have shown that the mix method was preferred for the analysis of Gram-positive bacteria. ${ }^{13}$ This clearly highlights that one sample analysis method does not exist for the analysis of all bacteria.

\section{Multivariate analysis}

In this review we have introduced and discussed three different physicochemical bioanalytical techniques that are used for bacterial typing. All of these produce a large number of characteristics about the sample under analysis. For FT-IR and Raman these consist of thousands of complex vibrational modes either from absorption of infrared light at a particular wavelength (expressed as wavenumber), or from the shift in the frequency of light from a laser excitation source in Raman spectroscopy. For MALDI these data are representative of the relative amounts of particular analytes (peptides, proteins, lipids, etc.) with particular $m / z$. Thus, multivariate analysis is needed in order to transform these spectra into useful outputs that aid clinical microbiology.

The central principle of multivariate analysis (MVA) relies on simplifying the data to a smaller number of variables without compromising the information content within the original data input, with the hope that this helps enhance scientific reasoning. For bacterial characterisation and typing there are generally two approaches: unsupervised methods that perform exploratory analysis; and supervised learning methods that aim to effect identification of bacteria from a spectral input. In general, unsupervised methods use only the spectral input variables (X-data), whilst supervised methods aim to take the X-data as input variables and associate these data with a set of target output variables (Y-data) which encode the identity of a set of bacteria of interest. $^{83}$

Perhaps the most popular unsupervised method is principal component analysis (PCA) which is used to reduce data dimensionality and as an exploratory analysis shows structure in the data by clustering spectra into groups with similar characteristics, as well as being used to discover outliers. PCA is not used to identify bacteria from their spectral profiles and so in general supervised models are used for bacterial classification from MS and spectroscopy data. The most popular ordination models are based on Fisher's linear discriminant analysis (LDA), and include discriminant function analysis (DFA; also termed canonical variate analysis (CVA)) and partial least squares-discriminant analysis (PLS-DA). ${ }^{183,184}$

There are various nonlinear equivalents to these LDA methods that perform nonlinear mapping from X-data (MS, IR, Raman) to Y-data (bacterial identity). These methods are generally referred to as machine learning techniques, with the most well-known referred to as: support vector machines (SVMs), random forests (RFs) and kernel PLS (kPLS) and for the interested reader a recent tutorial review highlights these alogorithms. ${ }^{185}$ Recently the interest in artificial intelligence (AI) and artificial neural networks (ANNs) has grown and in turn given rise to in depth learning. A variety of layers are used in convolution neural networks, which are essentially different to the single layer neural networks developed by Rumelhart and colleagues. ${ }^{186,187}$ Finally, whilst supervised learning methods are very powerful, they are not infallible and so need to be robustly calibrated. It is vital that the number of latent variables is selected carefully, and that supervised models are validated through (e.g.) bootstrapping or $n$-fold cross-validation, preferably tested with data not used at all in model construction. ${ }^{185}$ Only then can precise prediction,

Table 3 Comparison of the characteristics of various vibrational and mass spectrometric techniques

\begin{tabular}{|c|c|c|c|}
\hline $\begin{array}{l}\text { Analytical technique } \\
\text { Techniques characteristics }\end{array}$ & FT-IR spectroscopy & Raman spectroscopy & MALDI-MS \\
\hline Cost of running per sample & Low & Low & Low \\
\hline Automation & Yes & Yes & Yes \\
\hline Sample preparation & Minimum & Minimum & $\begin{array}{l}\text { Minimum/moderate } \\
\text { (depending on biomolecule/matrix) }\end{array}$ \\
\hline Amount of sample required & $1-2 \mu \mathrm{L}$ & $1 \mu \mathrm{L}$ & $2 \mu \mathrm{L}$ \\
\hline Single cell analysis possible? & No (but possible with AFM-IR and $O$-PTIR) ${ }^{a}$ & Yes & No \\
\hline Analysis time & $1 \mathrm{~min}$ & $1 \mathrm{~min}$ & $2 \min$ \\
\hline Reproducibility & Good & Medium & Medium \\
\hline Sensitivity & High & High & High \\
\hline Destructive of sample & No & No & Yes \\
\hline Size of generated data & Small & Small & Average \\
\hline Complexity of data & Low & Average & Average \\
\hline
\end{tabular}

${ }^{a}$ AFM-IR, atomic force microscopy coupled with infrared; O-PTIR, optical photothermal infrared. 
Table 4 Advantages and disadvantages of vibrational and mass spectrometric techniques used in characterisation of bacteria

\begin{tabular}{|c|c|c|}
\hline Method & Advantages & Disadvantages \\
\hline FT-IR & $\begin{array}{l}\text { - Easy sample preparation } \\
\text { - Simple to use } \\
\text { - Sensitive technique } \\
\text { - Provides general information about whole-bacterial cells } \\
\text { - Rapid analysis } \\
\text { - Portability }\end{array}$ & $\begin{array}{l}\text { - May need expertise in chemometric analysis of data } \\
\text { - The water band is very strong so the sample needs to be dried } \\
\text { - Different conditions (e.g. growth time and culture medium) can } \\
\text { cause variations in spectra }\end{array}$ \\
\hline Raman & $\begin{array}{l}\text { - Provides information on biological structures } \\
\text { - Able to analyse small quantities of samples } \\
\text { - Single cell analysis } \\
\text { - The water band is very weak } \\
\text { - Rapid } \\
\text { - Whole-cell molecular fingerprinting } \\
\text { - Portability }\end{array}$ & $\begin{array}{l}\text { - The Raman effect is weak leading to low sensitivity and long } \\
\text { collection times } \\
\text { - Interference with fluorescence } \\
\text { - Spectral bands affected by environmental conditions (e.g. pH, g } \\
\text { stage, etc.) }\end{array}$ \\
\hline MALDI-MS & $\begin{array}{l}\text { - Rapid and specific detection of whole bacteria } \\
\text { - Ability to analyse high molecular weight compounds } \\
\text { (e.g. proteins) in a wide mass range } \\
\text { - Generally unaffected by growth conditions, as } \\
\text { ribosomes are key discriminatory features in spectra } \\
\text { - Soft ionisation technique } \\
\text { - Sub-picomole sensitivity } \\
\text { - Wide array of matrices }\end{array}$ & $\begin{array}{l}\text { - MALDI matrix cluster ions obscure low } \mathrm{m} / \mathrm{z} \text { species }(<600 \mathrm{amu}) \\
\text { leading to matrix interference with small molecules } \\
\text { - Homogeneity from spot to spot is variable } \\
\text { - Compromised quantification }\end{array}$ \\
\hline
\end{tabular}

increased and reliable quality control, and assurance in disease diagnostics be provided. ${ }^{188}$

\section{Comparative assessment of these analytical techniques used in bacterial typing}

This review has highlighted several physicochemical techniques that can be used for bacterial characterisation. Each of these whole organism fingerprinting methods has advantages and disadvantages, and these must be explored prior to an analyst making an informed decision as to which tool to use.

Although different analytical techniques tend to provide a specific type of information, the choice of which to employ has so far been mostly guided by availability, cost and intended applications. Table 3 provides a comparative assessment of the performance of analytical techniques whilst Table 4 highlights the advantages and disadvantages of these techniques. Fig. 4 also emphasises the overall scheme of sample preparation and in particular the reasons for choosing one method over another. This is provided by a series of microbiological questions which are highlighted below:

- Typing to species level: for routine bacterial typing where the genus and species identification is needed then MALDI-MS is the technique of choice.

- Species/sub-species typing: whilst MALDI-MS is an excellent identification method for sub-species analysis, vibrational spectroscopy and in particular FT-IR spectroscopy is generally preferred, although we note that Raman spectroscopy can also be used for this purpose.

- Phenotypic characterisation: bacteria often adapt to their environment and this will be by changing the physiology and biochemistry of the sample. This is best measured using FT-IR spectroscopy, and Raman spectroscopy can also play a role here.

- Single cell analysis: for the analysis of single bacterial cells the preferred method of analysis is currently Raman spectroscopy. However new optical, photothermal, and infrared based spectroscopy methods are starting to emerge as illustrated in Fig. 3.

This information can aid experimental design in bacterial typing and identification applications, with the tantalising prospect of some techniques being able to measure single bacterial cells, which means that the clinician no longer needs to isolate the microorganism prior to testing. Importantly, several of these techniques provide complementary and confirmatory data, offering highly reliable phenotyping results and more comprehensive analysis of bioprocesses. The characteristics of the various analytical techniques that can be used to analyse bacteria as discussed in this review should be considered along with the type of sample and preparation method in order to ensure validity and reliability of the generated information.

\section{Conclusion and outlook}

The development in the analysis of bacterial samples using modern analytical techniques has been on the rise over recent decades due to several advantages, such as rapid analysis and accurate, and readily interpretable results, with more future improvements expected in sample preparation and methods of analysis from bulk bacterial samples to single cells. In this review we have aimed to provide insights into the applications of infrared and Raman spectroscopy as well as mass spectrometry for the characterisation and identification of bacterial samples from different sources. Currently within clinical 
microbiology laboratories MALDI-MS is the method of choice for bacterial identification. The success of this particular mass spectrometry technique is largely down to its robust analysis because it measures a small proportion of the bacterial cell namely the ribosomes, which are always present irrespective of how the bacteria are cultured.

One of the main challenges for the future is the desire to have even more rapid analysis by removing the need to enrich and isolate the bacteria or fungi prior to analysis. Here the high spatial resolution offered by both Raman spectroscopy and infrared micro-spectroscopy means that there is potential for single cell analysis, as illustrated in Fig. 3. The remaining challenge here will be the necessity to locate the microorganism prior to analysis. For some highly complex samples like soil or faeces this will be very problematic without the successful implementation of mechanical capture mechanisms.

The whole organism fingerprinting methods discussed within this review generate large amounts of high dimensional phenotypic data about the sample analysis. Therefore, it is essential that these techniques are combined with suitable chemometrics and machine learning to provide easily interpretable outputs. In the wake of the novel coronavirus (COVID-19) global pandemic, IR spectroscopy and Raman spectroscopy in parallel with multivariate chemometrics may play a crucial role in rapid and sensitive screening of RNA or glycoproteins for severe acute respiratory coronavirus-2 (SARS-CoV-2), ${ }^{189}$ the causative agent of COVID-19, that would potentially allow for timely intervention of appropriate patient care, reduction of mortality rate and continuous monitoring of COVID-19.

In summary, we believe that the powerful combination of whole organism fingerprinting methods with robust informatics will provide simple and efficient diagnostic and monitoring tools in many different areas including within the fields of medicine, the environment and food, and by biotechnological processes.

\section{Conflicts of interest}

There are no conflicts to declare.

\section{Acknowledgements}

This research was funded by the Deanship of Scientific Research at Princess Nourah bint Abdulrahman University through the Fast-track Research Funding Program to NA. HM, CAL and RG are grateful to the University of Liverpool for support.

\section{References}

1 R. W. Peeling, P. G. Smith and P. M. M. Bossuyt, Nat. Rev. Microbiol., 2006, 4, S2-S6.

2 J. Wilkinson, Nat. Toxins, 1999, 7, 221-232.

3 M. Sauer, D. Porro, D. Mattanovich and P. Branduardi, Trends Biotechnol., 2008, 26, 100-108.
4 S. Sauer and M. Kliem, Nat. Rev. Microbiol., 2010, 8, 74-82.

5 J. Perry, Clin. Microbiol. Rev., 2017, 30, 449-479.

6 V. Sintchenko, J. R. Iredell and G. L. Gilbert, Nat. Rev. Microbiol., 2007, 5, 464-470.

7 B. Holmes, W. Willcox and S. Lapage, J. Clin. Pathol., 1978, 31, 22-30.

8 E. Engvall, Med. Biol., 1977, 55, 193-200.

9 T. F. O'Sullivan and G. F. Fitzgerald, FEMS Microbiol. Lett., 1998, 168, 213-219.

10 H. AlRabiah, E. Correa, M. Upton and R. Goodacre, Analyst, 2013, 138, 1363.

11 J. H. Gross, Mass spectrometry: a textbook, Springer Science and Business Media, 2006.

12 M. J. Baker, H. J. Byrne, J. Chalmers, P. Gardner, R. Goodacre, A. Henderson and J. Sulé-Suso, Analyst, 2018, 143, 1735-1757.

13 N. AlMasoud, Y. Xu, N. Nicolaou and R. Goodacre, Anal. Chim. Acta, 2014, 840, 49-57.

14 J. W. Allwood, H. AlRabiah, E. Correa, A. Vaughan, Y. Xu, M. Upton and R. Goodacre, Metabolomics, 2015, 11, 438453.

15 S. Pahlow, S. Meisel, D. Cialla-May, K. Weber, P. Rösch and J. Popp, Adv. Drug Delivery Rev., 2015, 89, 105-120.

16 C. Quintelas, E. C. Ferreira, J. A. Lopes and C. Sousa, Biotechnol. J., 2018, 13, 1700449.

17 R. Goodacre, E. M. Timmins, R. Burton, N. Kaderbhai, A. M. Woodward, D. B. Kell and P. J. Rooney, Microbiology, 1998, 144, 1157-1170.

18 J. T. Magee, Whole-organism fingerprinting, in Handbook of New Bacterial Systematics, ed. M. Goodfellow and A. G. O'Donnell, Academic Press, London, 1996, pp. 383-427.

19 X. N. Lu, H. M. Al-Qadiri, M. S. Lin and B. A. Rasco, Food Bioprocess Technol., 2011, 4, 919-935.

20 J. P. Harrison and D. Berry, Front. Microbiol., 2017, 8, 675.

21 L. B. Kong, P. F. Zhang, P. Setlow and Y. Q. Li, Anal. Chem., 2010, 82, 3840-3847.

22 J. P. Maity, S. Kar, C. M. Lin, C. Y. Chen, Y. F. Chang, J. S. Jean and T. R. Kulp, Spectrochim. Acta, Part A, 2013, 116, 478-484.

23 D. I. Ellis, D. P. Cowcher, L. Ashton, S. O'Hagan and R. Goodacre, Analyst, 2013, 138, 3871-3884.

24 G. Sharma and A. Prakash, J. Microbiol., Biotechnol. Food Sci., 2020, 9, 310-314.

25 K. Maquelin, L. P. Choo-Smith, T. van Vreeswijk and H. P. Endtz, Anal. Chem., 2000, 72, 12-19.

26 H. Muhamadali, D. Weaver, A. Subaihi, N. AlMasoud, D. K. Trivedi, D. I. Ellis, D. Linton and R. Goodacre, Analyst, 2016, 141, 111-122.

27 K. Maquelin, L. Dijkshoorn, T. J. K. van der Reijden and G. J. Puppels, J. Microbiol. Methods, 2006, 64, 126-131.

28 H. Muhamadali, M. Chisanga, A. Subaihi and R. Goodacre, Anal. Chem., 2015, 87, 4578-4586.

29 A. C. McGovern, D. Broadhurst, J. Taylor, N. Kaderbhai, M. K. Winson, D. A. Small, J. J. Rowland, D. B. Kell and R. Goodacre, Biotechnol. Bioeng., 2002, 78, 527-538. 
30 D. P. Cowcher, Y. Xu and R. Goodacre, Anal. Chem., 2013, 85, 3297-3302.

31 M. Cheung, W. W. Y. Lee, D. P. Cowcher, R. Goodacre and S. E. J. Bell, Chem. Commun., 2016, 52, 9925-9928.

32 L. C. Thomas and J. E. S. Greenstreet, Spectrochim. Acta, 1954, 6, 302-319.

33 L. Mariey, J. P. Signolle, C. Amiel and J. Travert, Vib. Spectrosc., 2001, 26, 151-159.

34 D. Helm, H. Labischinski, G. Schallehn and D. Naumann, Microbiology, 1991, 137, 69-79.

35 D. Naumann, in Encyclopedia of Analytical Chemistry, John Wiley \& Sons, Ltd, 2006.

36 D. I. Ellis, W. B. Dunn, J. L. Griffin, J. W. Allwood and R. Goodacre, Pharmacogenomics, 2007, 8, 1243-1266.

37 R. Gurbanov, A. G. Gozen and F. Severcan, Spectrochim. Acta, Part A, 2018, 189, 282-290.

38 H. Muhamadali, A. Subaihi, M. Mohammadtaheri, Y. Xu, D. I. Ellis, R. Ramanathan, V. Bansal and R. Goodacre, Analyst, 2016, 141, 5127-5136.

39 B. H. Stuart, in Encyclopedia of Analytical Chemistry, John Wiley \& Sons, Ltd, 2006.

40 B. Stuart, Modern infrared spectroscopy, Chichester, 1996.

41 C. Berthomieu and R. Hienerwadel, Photosynth. Res., 2009, 101, 157-170.

42 D. Naumann, D. Helm and H. Labischinski, Nature, 1991, 351, 81-82.

43 H. AlRabiah, J. W. Allwood, E. Correa, Y. Xu and R. Goodacre, PLoS One, 2018, 13, e0200272.

44 H. AlRabiah, Y. Xu, N. J. Rattray, A. A. Vaughan, T. Gibreel, A. Sayqal and R. Goodacre, Analyst, 2014, 139, 4193-4199.

45 N. M. Amiali, M. R. Mulvey, B. Berger-Bächi, J. Sedman, A. E. Simor and A. A. Ismail, J. Antimicrob. Chemother., 2008, 61, 95.

46 G. D. Sockalingum, W. Bouhedja, P. Pina, P. Allouch, C. Mandray, R. Labia, J. M. Millot and M. Manfait, Biochem. Biophys. Res. Commun., 1997, 232, 240.

47 N. Jin, D. Zhang and F. L. Martin, Integr. Biol., 2017, 9, 406-417.

48 N. Jin, M. Paraskevaidi, K. T. Semple, F. L. Maryin and D. Zhang, Anal. Chem., 2017, 89, 9814.

49 A. Novais, A. R. Freitas, C. Rodrigues and L. Peixe, Eur. J. Clin. Microbiol., 2019, 38, 427-448.

50 P. Zarnowiec, L. Lechowicz, G. Czerwonka and W. Kaca, Curr. Med. Chem., 2015, 22, 1710-1718.

51 A. Salman, L. Tsror, A. Pomerantz, R. Moreh, S. Mordechai and M. Huleihel, Spectroscopy, 2101, 24, 261-267.

52 K. Forfang, B. Zimmermann, G. Kosa, A. Kohler and V. Shapaval, PLoS One, 2017, 12, e0170611.

53 J. Lee, M. S. Ahn, Y. L. Lee, E. Y. Jie, S. G. Kim and S. W. Kim, J. Appl. Microbiol., 2019, 126, 864-871.

54 C. A. Rebuffo, J. Schmitt, M. Wenning, F. von Stetten and S. Scherer, Appl. Environ. Microbiol., 2006, 72, 994-1000.

55 A. O. Janbu, T. Møretrø, D. Bertrand and A. Kohler, FEMS Microbiol. Lett., 2008, 278, 164.

56 Y. D. Wang, X. L. Li, J. Hu and J. H. Lü, Nucl. Sci. Tech., 2019, 30, 25.
57 V. Shapaval, J. Schmitt, T. Møretrø, H. Suso, I. Skaar, D. Lillehaug and A. Kohler, J. Appl. Microbiol., 2013, 114, 788-796.

58 V. Shapaval, T. Møretrø, A. Wold, H. Suso, J. Schmitt, D. Lillehaug and A. Kohler, Lett. Appl. Microbiol., 2016, 64, 335-34259.

59 K. Maquelin, C. Kirschner, L. P. Choo-Smith, N. A. NgoThi, T. van Vreeswijk, M. Stämmler, H. P. Endtz, H. A. Bruining, D. Naumann and G. J. Puppels, J. Clin. Microbiol., 2003, 41, 324-329.

60 M. Bağcıoğlu, M. Fricker, S. Johler and M. Ehling-Schulz, Front. Microbiol., 2019, 10, 902.

61 A. Hornemann, D. Sinning, S. Cortes, L. Campino, P. Emmer, K. Kuhls, G. Ulm, M. Frohme and B. Beckhoff, Anal. Bioanal. Chem., 2017, 409, 6907-6923.

62 C. D. Kaptchouang Tchatchouang, J. Fri, M. De Santi, G. Brandi, G. F. Schiavano, G. Amagliani and C. N. Ateba, Microorganisms, 2020, 8, 135.

63 K. F. Romanolo, L. Gorski, S. Wang and C. R. Lauzon, PLoS One, 2015, 10, e0143425.

64 S. F. Lin, H. Schraft and M. W. Griffiths, J. Food Prot., 1998, 61, 921-923.

65 S. H. Beattie, C. Holt, D. Hirst and A. G. Williams, FEMS Microbiol. Lett., 1998, 164, 201.

66 A. Al-Mariri, L. Ramadan, A. Younes and A. Al-Laham, Bulg. J. Vet. Med., 2019, 22, 285-296.

67 S. Treguier, C. Couderc, H. Tormo, D. Kleiber and C. Levasseur-Garcia, J. Microbiol. Methods, 2019, 165, 105693.

68 H. Oberreuter and J. Rau, FEMS Microbiol. Lett., 2019, 366, fnz193.

69 G. Abu-Aqil, L. Tsror, E. Shufan, S. Mordechai, M. Huleihel and A. Salman, J. Biophotonics, 2020, 13, e201960156.

70 K. Kochan, C. Nethercott, J. Taghavimoghaddam, Z. Richardson, E. Lai, S. Crawford, A. Y. Peleg, B. R. Wood and P. Heraud, Anal. Chem., 2020, 92, 8235-8243.

71 M. J. Baker, J. Trevisan, P. Bassan, R. Bhargava, H. J. Butler, K. M. Dorling, P. R. Fielden, S. W. Fogarty, N. J. Fullwood, K. A. Heys, C. Hughes, P. Lasch, P. L. Martin-Hirsch, B. Obinaju, G. D. Sockalingum, J. Sulé-Suso, R. J. Strong, M. J. Walsh, B. R. Wood, P. Gardner and F. L. Martin, Nat. Protocols, 2014, 9, 17711791.

72 M. J. Walsh, M. N. Singh, H. M. Pollock, L. J. Cooper, M. J. German, H. F. Stringfellow, N. J. Fullwood, E. Paraskevaidis, P. L. Martin-Hirsch and F. L. Martin, Biochem. Biophys. Res. Commun., 2007, 352, 213-219.

73 C. S. Ho, N. Jean, C. A. Hogan, L. Blackmon, S. S. Jeffrey, M. Holodniy, N. Banaei, A. A. Saleh, S. Ermon and J. Dionne, Nat. Commun., 2019, 10, 1-8.

74 P. E. Fournier, M. Drancourt, P. Colson, J. M. Rolain, B. L. Scola and D. Raoult, Nat. Rev. Microbiol., 2013, 11, 574-585.

75 D. I. Ellis, H. Muhamadali, S. A. Haughey, C. T. Elliott and R. Goodacre, Anal. Methods, 2015, 7, 9401-9414. 
76 H. J. Butler, L. Ashton, B. Bird, G. Cinque, K. Curtis, J. Dorney, K. Esmonde-White, N. J. Fullwood, B. Gardner, P. L. Martin-Hirsch, M. J. Walsh, M. R. McAinsh, N. Stone and F. L. Martin, Nat. Protocols, 2016, 11, 664-687.

77 T. Vankeirsbilck, A. Vercauteren, W. Baeyens, G. Van der Weken, F. Verpoort, G. Vergote and J. P. Remon, Trends Anal. Chem., 2002, 21, 869-877.

78 S. Pahlow, S. Meisel, D. Cialla-May, K. Weber and J. P. P. Röschac, Adv. Drug Delivery Rev., 2015, 89, 105-120.

79 S. Lohumi, H. Lee and B.-K. Cho, Trends Food Sci. Technol., 2015, 46, 85-98.

80 M. Chisanga, D. Linton, H. Muhamadali, D. I. Ellis, R. L. Kimber, A. Mironov and R. Goodacre, Analyst, 2020, 145, 1236-1249.

81 A. V. Vlasov, N. L. Maliar, S. V. Bazhenov, E. I. Nikelshparg, N. A. Brazhe, A. D. Vlasova, S. D. Osipov, V. V. Sudarev, Y. L. Ryzhykau, A. O. Bogorodskiy and E. V. Zinovev, Crystals, 2020, 10, 38.

82 S. D. Dryden, S. Anastasova, G. Satta, A. J. Thompson, D. R. Leff and A. Darzi, Int. Soc. Opt. Photonics, 2020, 11247, 1124705.

83 M. Chisanga, H. Muhamadali, D. I. Ellis and R. Goodacre, Appl. Sci., 2019, 9, 1163.

84 J. R. Baena and B. Lendl, Curr. Opin. Chem. Biol., 2004, 8, 534-539.

85 J. De Gelder, K. De Gussem, P. Vandenabeele and L. Moens, J. Raman Spectrosc., 2007, 38, 1133-1147.

86 T. Hellerer, C. Axäng, C. Brackmann, P. Hillertz, M. Pilon and A. Enejder, Proc. Natl. Acad. Sci. U. S. A., 2007, 104, 14658-14663.

87 H. G. Breunig, R. Bückle, M. Kellner-Höfer, M. Weinigel, J. Lademann, W. Sterry and K. König, Microsc. Res. Tech., 2012, 75, 492-498.

88 C. W. Freudiger, W. Min, B. G. Saar, S. Lu, G. R. Holtom, C. He, J. C. Tsai, J. X. Kang and X. S. Xie, Science, 2008, 322, 1857-1861.

89 G. Clemens, J. R. Hands, K. M. Dorling and M. J. Baker, Analyst, 2014, 139, 4411-4444.

90 W. E. Huang, M. Li, R. M. Jarvis, R. Goodacre and S. A. Banwart, in Advances in applied microbiology, Academic Press, 2010, vol. 70, pp. 153-186.

91 S. Kumar, R. Gopinathan, G. K. Chandra, S. Umapathy and D. K. Saini, Anal. Bioanal. Chem., 2020, 412, 25052516.

92 A. I. M. Athamneh, R. A. Alajlouni, R. S. Wallace, M. N. Seleem and R. S. Senger, Antimicrob. Agents Chemother., 2014, 58, 302-1314.

93 E. C. López-Díez and R. Goodacre, Anal. Chem., 2014, 76, 585-591.

94 E. C. López-Díez, C. L. Winder, L. Ashton, F. Currie and R. Goodacre, Anal. Chem., 2005, 77, 2901-2906.

95 H. Zhou, D. Yang, N. P. Ivleva, N. E. Mircescu, S. Schubert, R. Niessner, A. Wieser and C. Haisch, Anal. Chem., 2015, 87, 6553-6561.

96 D. Kusić, B. Kampe, P. Rösch and J. Popp, Water Res., 2014, 48, 179-189.
97 A. Assaf, E. Grangé, C. B. Y. Cordella, D. N. Rutledge, M. Lees, A. Lahmar and G. Thouand, Anal. Bioanal. Chem., 2020, 412, 595-3604.

98 J. Wang, X. Wu, C. Wang, N. Shao, P. Dong, R. Xiao and S. Wang, ACS Appl. Mater. Interfaces, 2015, 7, 2091920929.

99 C. Xie, J. Mace, M. A. Dinno, Y. Q. Li, W. Tang, R. J. Newton and P. J. Gemperline, Anal. Chem., 2005, 77, 4390-4397.

100 M. Harz, P. Rösch, K. D. Peschke, O. Ronneberger, H. Burkhardt and J. Popp, Analyst, 2005, 130, 1543-1550.

101 Z. Schmilovitch, A. Mizrach, V. Alchanatis, G. Kritzman, R. Korotic and J. Irudayaraj, Trans. ASAE, 2005, 48, 18431850 .

102 A. Subaihi, L. Almanqur, H. Muhamadali, N. AlMasoud, D. I. Ellis, D. K. Trivedi, K. A. Hollywood, Y. Xu and R. Goodacre, Anal. Chem., 2016, 88, 10884-10892.

103 M. Chisanga, H. Muhamadali, R. Kimber and R. Goodacre, Faraday Discuss., 2017, 205, 331-343.

104 M. Chisanga, H. Muhamadali, D. I. Ellis and R. Goodacre, Appl. Spectrosc., 2018, 72, 987-1000.

105 D. Graham, R. Goodacre, H. Arnolds, J. F. Masson, G. Schatz, J. Baumberg, D. H. Kim, J. Aizpurua, W. Lum, A. Silvestri and B. De Nijs, Faraday Discuss., 2017, 205, 173-211.

106 P. L. Stiles, J. A. Dieringer, N. C. Shah and R. P. Van Duyne, Annu. Rev. Anal. Chem., 2008, 1, 601-621.

107 S. Schlucker, Surface-Enhanced Raman Spectroscopy: Concepts and Chemical Applications, Angew. Chem., Int. Ed., 2014, 53, 4756-4795.

108 R. M. Jarvis and R. Goodacre, Anal. Chem., 2004, 76, 4047.

109 R. M. Jarvis, N. Law, I. T. Shadi, P. O’Brien, J. Lloyd and R. Goodacre, Anal. Chem., 2008, 80, 6741-6746.

110 J. Baumberg, S. Bell, A. Bonifacio, R. Chikkaraddy, et al., Faraday Discuss., 2017, 205, 429-456.

111 H. Kearns, R. Goodacre, L. E. Jamieson, D. Graham and K. Faulds, Anal. Chem., 2017, 89, 12666-12673.

112 R. Goodacre, D. Graham and K. Faulds, TrAC, Trends Anal. Chem., 2018, 102, 359-368.

113 K. C. Schuster, I. Reese, E. Urlaub, J. R. Gapes and B. Lendl, Anal. Chem., 2000, 72, 5529-5534.

114 B. Lorenz, C. Wichmann, S. Stöckel, P. Rösch and J. Popp, Trends Microbiol., 2017, 25, 413-424.

115 A. Dazzi, C. B. Prater, Q. Hu, D. B. Chase, J. F. Rabolt and C. Marcott, Appl. Spectrosc., 2012, 66, 1365-1384.

116 D. Zhang, C. Li, C. Zhang, M. N. Slipchenko, G. Eakins and J. X. Cheng, Sci. Adv., 2016, 2, e1600521.

117 M. Hesse, H. Meier and B. Zeeh, Spectroscopic Methods in Organic Chemistry, Thieme, Stuttgart, 2nd edn, 2008.

118 R. Goodacre and D. B. Kell, Curr. Opin. Biotechnol., 1996, 7, 20-28.

119 R. Goodacre, E. M. Timmins, R. Burton, N. Kaderbhai, A. M. Woodward, D. B. Kell and P. J. Rooney, Microbiology, 1998, 144, 1157-1170.

120 A. Fox, J. Clin. Microbiol., 2006, 44, 2677-2680. 
121 W. B. Dunn, A. Erban, R. J. M. Weber, D. J. Creek, M. Brown, R. Brietling, T. Hankemeier, R. Goodacre, S. Neumann, J. Kopka and M. R. Viant, Metabolomics, 2013, 9, S44-S66.

122 M. Karas and F. Hillenkamp, Anal. Chem., 1988, 60, 22992303.

123 L. Yin, Z. Zhang, Y. Liu, Y. Gao and J. Gu, Analyst, 2019, 144, 824-845.

124 S. Sauer, M. H. Bodo Lange, G. Johan, N. Lajos, S. Harald and L. Hans, Nat. Rev. Genet., 2005, 6, 465-476.

125 S. Vaidyanathan, D. B. Kell and R. Goodacre, J. Am. Soc. Mass Spectrom., 2002, 13, 118-128.

126 S. Vaidyanathan, J. J. Rowland, D. B. Kell and R. Goodacre, Anal. Chem., 2001, 73, 4134-4144.

127 T. Luzzatto-Knaan, A. V. Melnik and P. C. Dorrestein, Analyst, 2015, 140, 4949-4966.

128 B. Fuchs, R. Süß and J. Schiller, Prog. Lipid Res., 2010, 49, 450-475.

129 R. Giebel, C. Worden, S. M. Rust, G. T. Kleinheinz, M. Robbins and T. R. Sandrin, Adv. Appl. Microbiol., 2010, 71, 149-184.

130 N. AlMasoud, Y. Xu, N. Nicolaou and R. Goodacre, Anal. Chim. Acta, 2014, 840, 49-57.

131 P. Lasch, W. Beyer, H. Nattermann, M. Stammler, E. Siegbrecht, R. Grunow and D. Naumann, Appl. Environ. Microbiol., 2009, 75, 7229-7242.

132 A. Mewara, M. Sharma, T. Kaura, K. Zaman, R. Yadav and R. Sehgal, Parasites Vectors, 2018, 11, 281.

133 M. Kussmann, E. Nordhoff, H. Rahbek-Nielsen, S. Haebel, M. Rossel-Larsen, L. Jakobsen, J. Gobom, E. Mirgorodskaya, A. Kroll-Kristensen, L. Palm and P. Roepstorff, J. Mass Spectrom., 1997, 32, 593-601.

134 S. Bourcier, S. Bouchonnet and Y. Hoppilliard, Int. J. Mass Spectrom., 2001, 210, 59-69.

135 N. AlMasoud, E. Correa, D. K. Trivedi and R. Goodacre, Anal. Chem., 2016, 88, 6301-6308.

136 N. AlMasoud, Y. Xu, D. K. Trivedi, S. Salivo, T. Abban, N. J. W. Rattray, E. Szula, H. AlRabiah, A. Sayqal and R. Goodacre, Anal. Bioanal. Chem., 2016, 408, 78657878.

137 W. Yan, J. Qian, Y. Ge, K. Ye, C. Zhou and H. Zhang, Anal. Biochem., 2020, 592, 113582.

138 X. Xu, N. Xiao, M. Yang, Y. Su and Y. Guo, Talanta, 2020, 208, 120361.

139 A. E. Clark, E. J. Kaleta, A. Arora and D. M. Wolk, Clin. Microbiol. Rev., 2013, 26, 547-603.

140 T. R. Sandrin, J. E. Goldstein and S. Schumaker, Mass Spectrom. Rev., 2013, 32, 188-217.

141 A. Freiwald and S. Sauer, Nat. Protocols, 2009, 4, 732742.

142 B. Feng, H. Shi, F. Xu, F. Hu, J. He, H. Yang, C. Ding, W. Chen and S. Yu, Anal. Chim. Acta, 2020, 1111, 75-82.

143 A. Mukherjee, G. Banerjee, P. Mukherjee, A. K. Ray, G. Chandra and K. Ghosh, Microb. Pathog., 2019, 130, 146-155.
144 S. S. Rubakhin and J. V. Sweedler, Anal. Chem., 2008, 80, 7128-7136.

145 F. Calderón-Celis, J. R. Encinar and A. Sanz-Medel, Mass Spectrom. Rev., 2018, 37, 715-737.

146 R. Liyanage, J. Gidden, C. L. Wilkins and J. O. Lay Jr., Rapid Commun. Mass Spectrom., 2019, 1-10.

147 Y. Li, M. Shan, Z. Zhu, X. Mao, M. Yan, Y. Chen, Q. Zhu, H. Li and B. Gu, BMC Infect. Dis., 2019, 19, 941.

148 Y. Liu, Q. Cao and L. Li, Methods Enzymol., 2019, 626, 147-202.

149 D. Zhang, Y. Yang, Q. Qin, J. Xu, B. Wang, J. Chen, B. Liu, W. Zhang and L. Qiao, Anal. Chem., 2019, 91, 23522359.

150 J. Krismer, J. Sobek, R. F. Steinhoff, R. Brönnimann, M. Pabst and R. Zenobi, in Single Cell Metabolism, Humana, New York, NY, 2020, pp. 113-124.

151 C. Fenselau, Mass spectrometry for characterization of microorganisms, in ACS Symposium Series, American Chemical Society, Washington, DC, USA, 1993, ch. 1, vol. 541, pp. 1-7.

152 M. A. Claydon, S. N. Davey, V. Edwards-Jones and D. B. Gordon, Nat. Biotechnol., 1996, 14, 1584-1586.

153 R. D. Holland, J. G. Wilkes, F. Rafii, J. B. Sutherland, C. C. Persons, K. J. Voorhees and J. O. Lay, Rapid Commun. Mass Spectrom., 1996, 10, 1227-1232.

154 C. Lange, S. Schubert, J. Jung, M. Kostrzewa and K. Sparbier, J. Clin. Microbiol., 2014, 52, 4155-4162.

155 C. Axelsson, A. S. Rehnstam-Holm and B. Nilson, Infect. Dis., 2020, 52, 45-53.

156 M. L. DeMarco and C. A. D. Burnham, Am. J. Clin. Pathol., 2014, 141, 204-212.

157 S. Nakano, Y. Matsumura, Y. Ito, T. Fujisawa, B. Chang, S. Suga, K. Kato, T. Yunoki, G. Hotta and T. Noguchi, Eur. J. Clin. Microbiol. Infect. Dis., 2015, 34, 2191-2198.

158 K. Woods, D. Beighton and J. L. Klein, J. Med. Microbiol., 2014, 63, 1143-1147.

159 N. AlMasoud, Y. Xu, D. I. Ellis, P. Rooney, J. F. Turton and R. Goodacre, Anal. Methods, 2016, 8, 7603-7613.

160 Y. Zhu, L. Qiao, M. Prudent, A. Bondarenko, N. Gasilova, S. B. Möller, N. Lion, H. Pick, T. Gong, Z. Chen, P. Yang, L. T. Lovey and H. H. Girault, Chem. Sci., 2016, 7, 29872995.

161 E. N. Ilina, A. D. Borovskaya, M. M. Malakhova, V. A. Vereshchagin, A. A. Kubanova and A. N. Kruglov, J. Mol. Diagn., 2009, 11, 75-86.

162 R. Eddabra, P. Gilles and S. Jean-Michel, Microbiol. Res., 2012, 167, 226-230.

163 A. A. Alatoom, C. J. Cazanave, S. A. Cunningham, S. M. Ihde and R. Patel, J. Clin. Microbiol., 2012, 50, 160163.

164 R. T. Saffert, S. A. Cunningham, S. M. Ihde, K. E. M. Jobe, J. Mandrekar and R. Patel, J. Clin. Microbiol., 2011, 49, 887-892.

165 A. Verroken, M. Janssens, C. Berhin, P. Bogaerts, T. D. Huang and G. Wauters, J. Clin. Microbiol., 2010, 48, 4015-4021. 
166 A. El Khéchine, C. Couderc, C. Flaudrops, D. Raoult and M. Drancourt, PLoS One, 2011, 6, e24720.

167 O. Šedo, I. Sedláček and Z. Zdráhal, Mass Spectrom. Rev., 2010, 30, 417-434.

168 P. A. Demirev, Y. P. Ho, V. Ryzhov and C. Fenselau, Anal. Chem., 1999, 71, 2732-2738.

169 E. Elhanany, R. Barak, M. Fisher, D. Kobiler and Z. Altboum, Rapid Commun. Mass Spectrom., 2001, 15, 2110-2116.

170 V. Horneffer, J. Haverkamp, H. G. Janssen and R. Notz, J. Am. Soc. Mass Spectrom., 2004, 15, 1444-1454.

171 E. I. Shaw, H. Moura, A. R. Woolfitt, M. Ospina, H. A. Thompson and J. R. Barr, Anal. Chem., 2004, 76, 4017-4022.

172 C. J. Keys, D. J. Dare, H. Sutton, G. Wells, M. Lunt, T. McKenna, M. McDowall and H. N. Shah, Infect., Genet. Evol., 2004, 4, 221-242.

173 F. J. Pineda, M. D. Antoine, P. A. Demirev, A. B. Feldman, J. Jackman, M. Longenecke and J. S. Lin, Anal. Chem., 2003, 75, 3817-3822.

174 J. Ramirez and C. Fenselau, J. Mass Spectrom., 2001, 36, 929-936.

175 H. Moura, A. R. Woolfitt, M. G. Carvalho, A. Pavlopoulos, L. M. Teixeria, G. A. Satten and J. R. Barr, FEMS Immunol. Med. Microbiol., 2008, 53, 333-342.

176 M. L. Ochoa and P. B. Harrington, Anal. Chem., 2005, 77, 5258-5267.

177 J. J. Jones, M. J. Stump, R. C. Fleming, J. O. Lay and C. L. Wilkins, Anal. Chem., 2003, 75, 1340-1347.
178 S. Vaidyanathan, C. L. Winder, S. C. Wade, D. B. Kell and R. Goodacre, Rapid Commun. Mass Spectrom., 2002, 16, 1276-1286.

179 A. J. Madonna, F. Basile, I. Ferrer, M. A. Meetani, J. C. Rees and K. J. Voorhes, Rapid Commun. Mass Spectrom., 2002, 14, 2220-2229.

180 M. A. Domin, K. J. Welham and D. S. Ashton, Rapid Commun. Mass Spectrom., 1999, 13, 222-226.

181 G. C. Conway, S. C. Smole, D. A. Sarracino, R. D. Arbeit and P. E. Leopold, J. Mol. Microbiol. Biotechnol., 2001, 3, 103-112.

182 V. Ruelle, B. El Moualij, W. Zorzi, P. Ledent and E. De Pauw, Rapid Commun. Mass Spectrom., 2004, 18, 2013-2019.

183 S. Wold, K. Esbensen and P. Geladi, Chemom. Intell. Lab. Syst., 1987, 2, 37-52.

184 D. Granato, J. S. Santos, G. B. Escher, B. L. Ferreira and R. M. Maggio, Trends Food Sci. Technol., 2018, 72, 83-90.

185 P. S. Gromski, H. Muhamadali, D. I. Ellis, Y. Xu, E. Correa, M. L. Turner and R. Goodacre, Anal. Chim. Acta, 2015, 879, 10-23.

186 J. Schmidhuber, Neural Netw., 2015, 61, 85-117.

187 D. E. Rumelhart, J. L. McClelland and P. R. Group, Parallel Distributed Processing, Experiments in the Microstructure of Cognition, MIT Press, Cambridge, MA, USA, 1986, pp. 1-2.

188 D. I. Broadhurst and D. B. Kell, Metabolomics, 2006, 2, 171-196.

189 R. S. Khan and I. U. Rehman, Expert Rev. Mol. Diagn., 2020, 647-649. 